\title{
QUISQUEYA EN EL HUDSON: LA COMUNIDAD DOMINICANA EN WASHINGTON HEIGHTS
}

\author{
Jorge Duany*
}

\section{Resumen:}

Hasta la fecha, las investigaciones sobre la migracion internacional de la República Dominicana han subestimado la persistencia cultural, la identidad étnica, las relaciones interétnicas y el mantenimiento del idioma entre los migrantes. La mayoría de los académicos se ha concentrado en los orígenes, la composición y la incorporación de los dominicanos al mercado laboral de los Estados Unidos y Puerto Rico, Este ensayo enfoca su atención en la creación de una dentidad trasnacional entre los dominicanos en la ciudad de Nueva York, basado en el trabajo de campo en Washington Heigths, la mayor comunidad dominicana en los Estados Unidos. Los objetivos del proyecto incluían la descripción de los valores y las prácticas culturales dominantes entre los inmigrantes dominicanos, así como el análisis de su identidad étnica a través de la cultura popular. El trabajo de campo examinó la proposición básica de que los inmigrantes dominicanos definen, afirman y expresan una identidad étnica vigorosa mediante la cultura popular, especialmente el lenguaje diario, la música, la religión y la comida. El problema de la identidad de los migrantes se abordó desde un punto de vista etnográfico, a partir del estudio intensivo de una pequeña área geográfica utilizando la observación partícipe y las entrevistas personales. La comunidad bajo estudio fue un bloque de Washington Heigths, escogido intencionalmente para representar las principales características de la población domini-

* Jorge Duany, Departamento de Ciencias Sociales, Universidad del Sagrado Corazón, Santurce, Puerto Rico. 
cana en Nueva York. Los resultados documentaron el surgimiento de una identidad transnacional caracterizada por un apego ambivalente hacia la sociedad anfitriona y una orientación hacia la sociedad de origen.

\section{Palabras Claves:}

Identidad cultural, migración dominicana, identidad étnica, cultura popular, identidad transnacional.

\section{El Problema}

En años recientes, los inmigrantes internacionales han creado múltiples comunidades e identidades transnacionales. Con la creciente facilidad de viajar a través de fronteras nacionales, la migración circular y de retorno se ha hecho cada vez más común. El acceso a la transportación aérea ha permitido un contacto más frecuente entre los migrantes y sus parientes y amigos en el pars de origen. La penetración cultural de los medios de comunicación masiva ha integrado hasta los pueblos más remotos de los palses emisores en una amplia red de información internacional. Como consecuencia, amplios contingentes de trabajadores migrantes se mueven incesantemente entre sus territorios nacionales y la diáspora. Como señala Elsa Chaney (1987:3; mi traducción) para el caso caribeño, "La vida caribeña en la ciudad de Nueva York es el producto de los continuos movimientos circulares de gente, dinero, bienes materiales, cultura y estilos de vida e ideas hacia y desde la ciudad de Nueva York".

Las comunidades transnacionales se caracterizan por un flujo constante de personas en ambas direcciones, un sentido de identidad dual, un apego ambivalente a dos naciones y una extensa red de lazos de parentesco y amistad a través de fronteras políticas. Muchos migrantes no escogen entre la lealtad hacia la comunidad de origen o el país receptor, sino que mantienen lazos en ambos lugares. Como apunta Leo Chavez (1993:8), el hecho de vivir al otro lado de un borde político no significa necesariamente que los migrantes dejen de pertenecer a sus comunidades de origen. Más bien, significa el desarrollo de lealtades divididas y la creción de una comunidad imaginaria en la sociedad 374 
receptora. Esta situación contradice las predicciones de las teorfas antropologicas y sociológicas convencionales sobre la asimilación cultural de los inmigrantes en los países receptores (Portes y Zhou 1993). Cada vez es más difícil aceptar que el proceso de migración y asentamiento en un país extranjero conlleva la pérdida inevitable de la identidad étnica.

El éxodo de la República Dominicana a los Estados Unidos ilustra los dilemas culturales de la migración internacional contemporánea. Por un lado, los dominicanos han hecho un esfuerzo por incorporarse al mosaico étnico de la sociedad norteamericana; por otro lado, los inmigrantes han mantenido elementos importantes de su cultura nacional, como el idioma español y la religión católica. Muchos observadores han señalado que los dominicanos en Nueva York -o dominican-yorks, como los llaman sus compatriotas en la Isla- viven suspendidos entre dos mundos, dos islas, dos banderas, dos idiomas, dos estados nacionales (véase The New York Times 1991a; Grasmuck y Pessar 1991). Este ensayo explorará el sentido de pertenecer a dos países al mismo tiempo - en este caso, a la República Dominicana así como los Estados Unidosentre los dominicanos en Nueva York.

\section{Reseña de la literatura.}

En julio de 1992, un policía de la ciudad de Nueva York mató a un joven dominicano en la calle 162 de Washington Heigths. La muerte de José "Kiko" García, un supuesto narcotraficante y adicto a la cocaína, provocó tres días de disturbios violentos en la comunidad dominicana. Los medios de comunicación locales y nacionales cubrieron extensamente los motines callejeros, ocurridos poco después de las revueltas raciales en Los Angeles y justo una semana antes de la Convención Nacional del Partido Demócrata en Nueva York. ${ }^{1}$ En septiembre de 1992, un grupo xenófobo derechista asesinó a una doméstica en Madrid España. En enero de 1993, un comunicado de prensa anónimo denunció "la plaga dominicana" en San Juan, Puerto Rico.

1. Para una muestra de la cobertura local de los disturbios y sus consecuencias, véase el Village Voice (1992a, 1992b, 1992c). 
Estos eventos aparentemente no relacionados entre sí apuntan hacia una hostilidad común, ocasionalmente violenta, contra los inmigrantes dominicanos en varios países. A pesar de la atención pública generada por tales incidentes, y una considerable cantidad de investigaciones académicas sobre el éxodo dominicano, la vida cotidiana de la comunidad dominicana en Nueva York no se entiende bien. Por ejemplo, se sabe poco sobre las estrategias de sobrevivencia y adaptación de los inmigrantes a un ambiente urbano dominado por las tensiones raciales y la competencia étnica. Las relaciones entre los dominicanos y otras minorías como los afro-americanos y los puertorriqueños en los Estados Unidos no se han estudiado sistemáticamente. ${ }^{2}$

Las investigaciones sobre la migración dominicana han eludido los problemas de asentarse en una sociedad, ajustarse a una cultura ajena y adaptar la cultura original. Hasta ahora, la agenda de investigación de los estudios dominicanos en los Estados Unidos se ha concentrado en la incorporación de los migrantes al mercado laboral de la ciudad de Nueva York (véase Hernández 1989c para una reseña de estas investigaciones). La persistencia cultural, la identidad étnica, las relaciones interétnicas y el mantenimiento del idioma se han relegado a un segundo plano, excepto por algunos estudiosos que incorporan tales asuntos tangencialmente en sus marcos de referencia teóricos o metodólogicos (véase, por ejemplo, Grasmuck y Pessar 1991; Georges 1990, 1988, 1984; Pesar 1985; Sasen-Koob 1979; Garrison y Weiss 1979; Hendricks 1974). La literatura sobre la migración dominicana se refiere frecuentemente a la estructura de las unidades domésticas, la ideología del género, las redes de parentesco, las asociaciones voluntarias, la política migratoria y otras variables socioeconómicas, pero presta poca atención a la definición y conservación de la cultura popular en la vida cotidiana. Mi propia investigación de campo ha descuidado el análisis de la identidad étnica entre los dominicanos en Puerto Rico (Duany 1990, 1991, 1992). ${ }^{3}$

2. Para algunos datos recientes sobre las relaciones entre los grupos latinos en Nueva York, véase el informe del Institute for Puerto Rican Policy (1992).

3. Sin embargo, la cultura de otros migrantes caribeños, especialmente puertoriqueños, cubanos y haitianos, ha sido estudiada intensamente desde el lenguaje cotidiano y la música popular hasta la religión folklórica y los festivales callejeros. Para muestra de 
Hasta la fecha, la literatura sobre la migración internacional de la República Dominicana ha estado prácticamente obsesionada con las características socioeconómicas de los migrantes dominicanos como trabajadores de clase baja. Como resultado, la evidencia disponible sugiere que el éxodo dominicano está motivado económicamente y deprivado culturalmente. Los estudios usualmente retratan a los dominicanos en Nueva York como obreros desculturados, interesados solamente en mejorar sus condiciones materiales de vida. A pesar del éxito popular del merengue y otras formas tradicionales de la cultura dominicana, pocos académicos se han ocupado de la identidad étnica de los migrantes. ${ }^{4}$

En síntesis, la literatura académica deja sin contestar varias preguntas fundamentales sobre la comunidad dominicana en Nueva York: ¿Cómo han modificado los migrantes sus valores y prácticas tradicionales en respuesta a un ambiente ajeno? ¿Hasta qué punto han forjado una nueva identidad étnica a partir de su cultura nacional y su percepción pública como una minoría racial en los Estados Unidos? ¿Cómo se relacionan los dominicanos con otros grupos étnicos y raciales en la ciudad de Nueva York, particularmente los afro-americanos y otros hispanos? Y finalmente, ¿cuán lejos han avanzado los dominicanos en el camino hacia la asimilación lingüística y cultural en los Estados Unidos? Tales preguntas subrayan la necesidad de realizar más trabajo de campo con la mayor comunidad dominicana en los Estados Unidos, Washington Heights. ${ }^{5}$

tales estudios, véanse los ensayos etnográficos recopilados por Sutton y Chaney (1987).

4. Ironicamente, la ciudad de Nueva York recientemente se ha convertido en el centro comercial de la industria musical dominicana. Para una aproximación periodística a la cultura musical de los migrantes dominicanos, véase McLain (1991). El documental de Sonia Fritz, Visa para un sueño en Nueva York (en preparación), promete retratar la vida cotidiana y la cultura popular de los dominicanos en Nueva York.

5. Domínguez $(1973,1978)$, hendricks (1984), Georges $(1984,1988)$ y Mahler (1989) han realizado investigaciones etnográficas con la comunidad dominicana en Washington Heights. Sin embargo, estos estudios han enfocado su atención en la clasificación racial, las redes sociales, las asociaciones voluntarias y el proceso de legalización, no en la identidad étnica, la cultura popular y la vida cotidiana como tal. 
Washington Heights es un vecindario multiétnico del alto Manhattan que actualmente alberga a alrededor de una tercera parte de todos los dominicanos en la ciudad de Nueva York (Necos 1993). Los asentamientos dominicanos se han aglomerado en el lado noroeste de Manhattan, desde la Calle 110 hasta la 190, al este de Broadway, con varias concentraciones menores en el sur del Bronx, el lado sureste de Manhattan y la sección de Corona en Queens. En la década de 1960, Washington Heights se convirtio en un barrio predominantemente hispanohablante, con una proporción parecida de cubanos, puertorriqueños y dominicanos (Domínguez 1973, 1978). Durante la década de 1970, los dominicanos desplazaron a muchos residentes antiguos del vecindario, especialmente judíos, irlandeses, griegos, puertorriqueños y cubanos. El predominio numérico de los dominicanos se acentuó en los años ochenta. Entre 1983 y 1989, más de 40,000 dominicanos se asentaron en Washington Heights y los vecindarios adyacentes de Inwood y Hamilton Heights (New York City, Department of City Planning 1992). No obstante, Washington Heights aún contiene muchos residentes afro-americanos, así como un número significativo de ecuatorianos, salvadoreños, colombianos y otros latinoamericanos.

Hoy en día, Washington Heights es mayormente un enclave dominicano dentro del centro de la ciudad, segregado de los blancos y negros no hispanos, y cada vez más de otros grupos hispanos establecidos en Nueva York. La concentración geográfica, la especialización económica y la solidaridad étnica han producido una gran cantidad y variedad de asociaciones dominicanas en Washington Heights (Sainz 1990; Georges 1988; Sassen-Koob 1979). En 1991, Washington Heights eligio a su primer representante dominicano al Consejo Municipal, el antiguo maestro Guillermo Linares, comenzando así un proceso de empoderamiento político. Culturalmente, el vecindario ha reproducido múltiples aspectos del estilo de vida y las instituciones tradicionales de los dominicanos, tales como partidos políticos y sindicatos. El vecindario se conoce actualmente como Quisqueya Heights, haciendo referencia al nombre indígena de la Isla de la Española (Larancuet et al. 1991).

Algunos académicos creen que los dominicanos han creado una incipiente economía de enclave en Washington Heights, caracterizada 378 
por una próspera red de pequeñas empresas orientadas hacia los inmigrantes (Portes y Guarnizo 1991; Hernández 1989a). Según Alejandro Portes y Luis Guamizo (1991), los dominicanos son dueños de más de 20,000 negocios en Nueva York, especialmente bodegas, agencias de taxi, talleres de costura, agencias de viaje y restaurantes. Un estudio reciente encontró un promedio de 12 negocios dominicanos por bloque entre las calles 157 y 181 del alto Manhattan (Mahler 1989). Sin embargo, la inmensa mayoría de los dominicanos en Nueva York son trabajadores de cuello azul y de servicios, empleados mayormente en la manufactura liviana, especialmente la industria del vestido (Pessar 1987). En suma, Washington Heights es predominantemente una comunidad de clase trabajadora, aunque con un elemento empresarial importante. Es dentro del contexto de la proletarización de la mayoría de los inmigrantes dominicanos en Nueva York que debe analizarse su identidad étnica y específicamente su cultura popular.

\section{Enfoque conceptual}

La cultura popular consiste en los valores compartidos y las prácticas cotidianas de los grupos subordinados dentro de una sociedad estratificada. La cultura popular bajo el capitalismo representa una adaptación de la clase trabajadora al orden establecido, que estructura sus condiciones de trabajo, relaciones familiares y actividades recreativas (García Canclini 1982). La cultura popular le da un significado simbólico a la vida cotidiana al comunicarle a uno mismo y a los demás cómo se inserta en el sistema social. El análisis de la cultura popular es, por lo tanto, esencial para interpretar las condiciones de vida de los trabajadores migrantes. Los estudios de los migrantes dominicanos deben examinar cómo éstos construyen su identidad étnica al recrear su cultura popular en el país receptor.

La cultura popular refleja y acentúa las divisiones de clase, raza, etnia, género, edad y otras categorías. Pero la cultura popular también muestra señales de subvertir la subordinación, proponiendo una ideologfa alterna a la de los grupos dominantes (Fiske 1989). En este contexto, el estudio de la cultura popular requiere entender cómo la gente usa los productos culturales del capitalismo, constantemente buscando sentido para su vida cotidiana. Es importante determinar si los dominicanos 
están asimilándose rápidamente a la cultura dominante en los Estados Unidos, o si se resisten a seguir el camino trazado por otros grupos de inmigrantes previos. La cultura popular de los inmigrantes dominicanos es proletaria porque la produce y consume una población subordinada por clase dentro del sistema capitalista norteamericano; pero también es étnica porque la practican inmigrantes de otro país. Esta intersección entre la clase y la etnia como puntos de referencia para la cultura popular es digna de mayor reflexión.

Desde esta perspectiva, la cultura popular provee terreno fértil para estudiar la compleja interacción entre la conformidad y la resistencia a la ideologia dominante por las clases subordinadas de la sociedad. A través de prácticas culturales como las narrativas orales, los bailes populares y las tradiciones religiosas, los sectores populares constantemente rehacen sus signos de identidad e impiden su absorción completa a la estructura de poder hegemónico (Rowe y Schelling 1991). De esta manera, el estudio de la cultura popular entre los dominicanos en Nueva York ilumina el potencial de la vida cotidiana para desafiar y transformar el orden establecido. La continua afirmación de una identidad propia puede proveerle un sentido de empoderamiento a la comunidad dominicana de Nueva York y promover la acción social y política a su favor. En suma, cualquier estudio que no incorpore la visión de mundo de los migrantes está incompleto. Como argumentó el fenecido historiador Gordon K. Lewis (1982:21-22; mi traducción), hay un tipo de estudio de los migrantes que ve la migración pero no al migrante, tal y como hay un tipo de estudio de la esclavitud que ve la esclavitud pero no al esclavo. Tenemos que ver la persona individual detrás de la máscara general [...] cada uno [de esos migrantes] viene con su propia visión del mundo que él o ella habita. Es nuestro deber, como académicos profesionales, descubrir ese cuadro y apreciar su importancia.

\section{Hipótesis}

Este ensayo examinará las siguientes proposiciones:

1. Los valores y las prácticas culturales de los inmigrantes domini- 
canos en Washington Heights se orientan primordialmente hacia la República Dominicana.

2. La comunidad dominicana de Washington Heights ha creado una identidad transcultural como resultado de la migración y el asentamiento en un ambiente hostil.

3. La cultura popular dominicana expresa una vigorosa identidad étnica, a través del lenguaje diario, la música, la religión y la comida.

4. Los inmigrantes dominicanos han elaborado los símbolos de su identidad nacional al margen de la cultura dominante en los Estados Unidos.

5. La mayoría de los dominicanos en Washington Heights se resiste a asimilarse a la cultura norteamericana y se mantiene apegada a su lengua y cultura de origen.

\section{Método ${ }^{6}$}

Muestra. La muestra para este estudio consistió en un bloque de Washington Heights, definido como el Distrito de Planificación 12 de Manhattan. El bloque se escogio por su alta concentración de residentes dominicanos, uso primordialmente residencial y seguridad. Debido a que el bloque se seleccionó intencionalmente, los resultados de esta investigación no pueden generalizarse más allá de la población bajo estudio. Sin embargo, pueden generarse conclusiones válidas sobre la identidad étnica, la cultura popular y la vida cotidiana de los dominicanos en Washington Heights. La muestra incluyó todas las unidades de vivienda y las personas residentes en cuatro edificios dentro del bloque desde el 14 de junio hasta el 25 de julio de 1993. El bloque contenía 126 unidades de vivienda y 352 personas. La comunidad bajo estudio era un

6. Esta investigación siguió las guías para una enumeración alterna preparadas por el Centro para la Investigación de Métodos de Encuesta del Negociado del Censo (Brownrigg 1990; Browning y Fansler 1990). Nuestro trabajo del campo anterior con los dominicanos en Puerto Rico se basó en esta estrategia de investigación (Duany, Hernández Angueira y Rey 1993). 
vecindario urbano, concentrado étnicamente, con una población predominantemente hispana, principalmente de origen dominicano.

El Cuadro 1 resume las características demográficas de la muestra. La muestra contiene ligeramente más mujeres que hombres, una mayoría de personas jóvenes y una mayor proporción de personas casadas que solteras. Estos datos demográficos revelan una comunidad relativamente estable, a pesar del impacto continuo de la inmigracion. Clasificamos a dos terceras partes de los residentes como mulatos, lo cual concuerda con el predominio de la mezcla racial en la población dominicana. Cuatro de cada cinco residentes eran de origen dominicano; más de la mitad había nacido en la República Dominicana. Más de tres cuartas partes habían nacido en ciudades grandes como Nueva York y Santo Domingo, confirmando el origen urbano de la mayoria de los dominicanos en los Estados Unidos. Las mujeres encabezaban más de la mitad de los hogares, con o sin sus maridos presentes. En suma, las características demográficas de la muestra son semejantes a las de la población dominicana en Nueva York. 


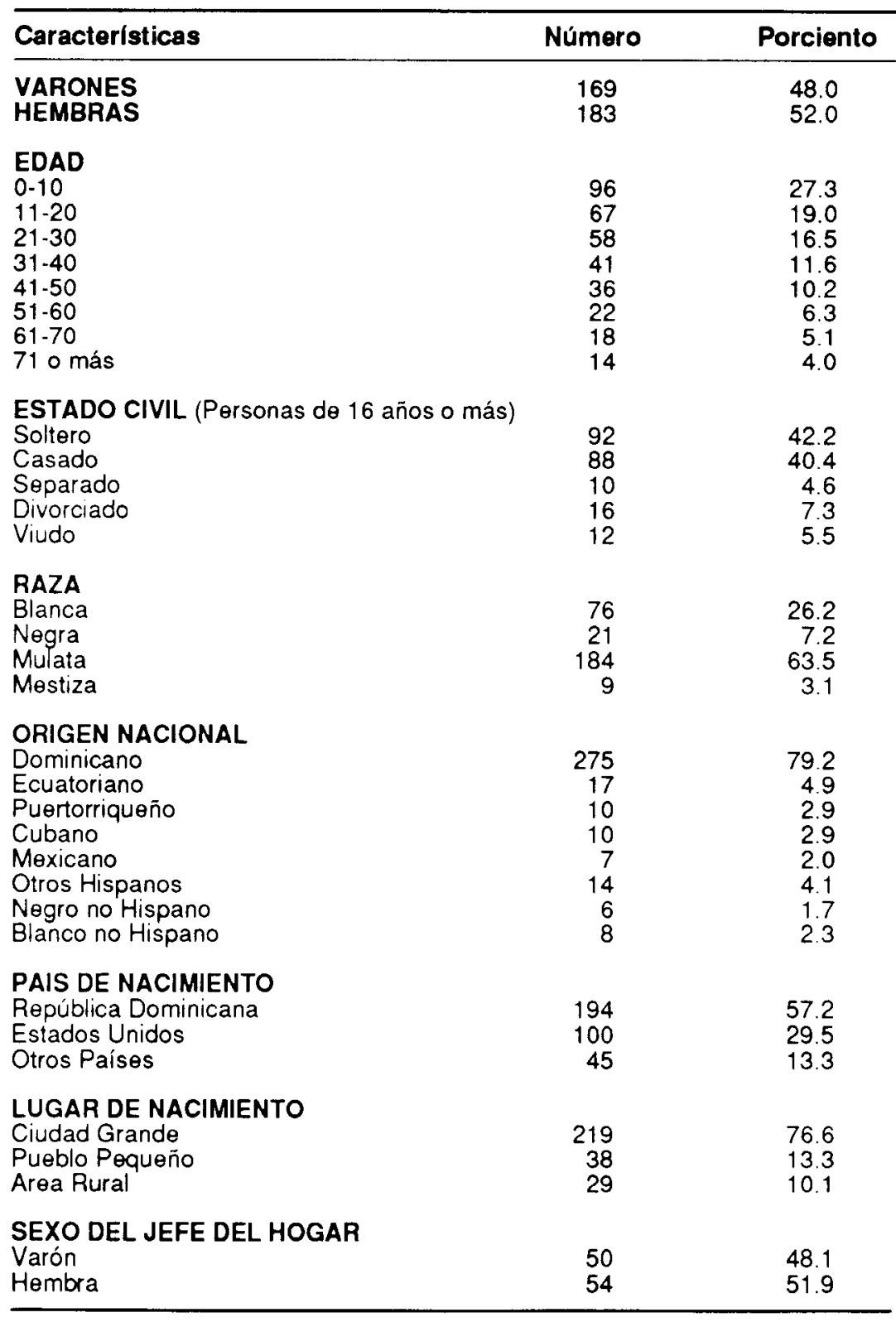

Nota: $N=352$. Falta información para 16 a 66 casos, dependiendo de la variable. 
Un estudio reciente provee datos comparativos sobre la comunidad dominicana de Washington Heights, basados en el Censo de 1990 de la ciudad de Nueva York (Necos 1993). Este estudio encontró que aproximadamente el 25 por ciento de la población de Washington Heights eran dominicanos, 19 por ciento otros hispanos, 25 por ciento afro-americanos, 26 por ciento blancos no hispanos y 3 por ciento asiáticos. De modo que nuestro bloque representa un vecindario predominantemente dominicano, con pequeñas proporciones tanto de blancos como negros no hispanos. Por lo demás, el bloque es típico de la población dominicana de Washington Heights, compuesta principalmente de inmigrantes recientes, relativamente jóvenes, mayormente nacidos en el extranjero, primordialmente hispanohablantes, con un alto nivel de pobreza y muchos hogares encabezados por mujeres.

\section{Instrumentos.}

El trabajo de campo se basó en la observación partícipe y las entrevistas personales. Nuestras observaciones se enfocaron en las características socioculturales de los residentes, así como de sus hogares y el vecindario. Tomamos notas de campo detalladas sobre las creencias, valores, prácticas y relaciones de los dominicanos con otros grupos étnicos. En particular, concentramos nuestra atención en las actitudes y conductas relacionadas con el lenguaje diario, la música. la religión y la comida. Siete investigadores realizaron observaciones estructuradas sobre estos asuntos en múltiples ocasiones durante seis semanas de trabajo de campo en el vecindario. Todas las notas de campo se integraron en una sola base de datos, produciendo más de 160 páginas de texto mecanografiadas a espacio sencillo.

Por otra parte, censamos a la mayoría de los hogares de la muestra y recogimos datos demográficos y socioeconómicos básicos sobre cada miembro. Estos datos incluyeron el sexo, la edad, el estado civil, la relación con el jefe del hogar, la ocupación y la rama económica. Además, determinamos el lugar de nacimiento y el origen nacional de los residentes. La raza, un asunto particularmente delicado entre los dominicanos, se observó en vez de preguntársela a los informantes. Al igual que en el resto del Caribe, los conceptos raciales en la República 
Dominicana establecen más distinciones sociales que en los Estados Unidos. Por lo tanto, clasificamos a la gente en cuatro categorías básicas según su apariencia física: blanco, negro, mulato o mestizo. Aunque este sistema de clasificación no es científico, provee un estimado aproximado de la composición racial del vecindario, de acuerdo con estándares locales.?

Por último, disenamos dos formatos de entrevista intensiva para indagar sobre los temas de interés central para esta investigación: la definición y afirmación de la identidad étnica, y las prácticas culturales en la vida cotidiana. La primera parte de la entrevista consistía en preguntas abiertas y cerradas sobre cómo los dominicanos se veían a sí mismos y a otros grupos, y si se afiliaban o no a algunas asociaciones voluntarias en Nueva York. La segunda parte de la entrevista se enfocaba en las prácticas culturales de los hogares dominicanos, particularmente su lenguaje diario, religión, música y comida. La entrevista también incluía preguntas sobre la ocupación actual y anterior de los inmigrantes, así como el origen nacional de los patronos y empleados en su centro de trabajo. En conjunto, estos instrumentos arrojaron mucha luz sobre cómo los dominicanos articulan su identidad mediante la cultura popular. Las entrevistas se efectuaron tanto en español como en inglés. dependiendo del idioma de preferencia de los informantes. La mayoría de las entrevistas se completó en la entrada o la sala de los apartamentos de los residentes.

Procedimiento. Para empezar, recorrimos el área definida como Washington Heights por el Departamento de Planificación Urbana de Nueva York y seleccionamos un bloque dentro del área. Este bloque era representativo de las características socioeconómicas del barrio, así como accesible a nuestra investigación. Evitamos los bloques predominantemente comerciales y los que sospechamos que tenían altas tasas de criminalidad. Decidimos enfocamos en cuatro edificios contiguos dentro del bloque para aumentar el contacto diario con los residentes.

7. En el censo de 1990, sólo el 26 por ciento de los dominicanos en la ciudad de Nueva York se clasificaron a sí mismos como negros (New York Newsday 1993e). La mayoría de los dominicanos se considera a sí misma blanca o mulata. 
Posteriormente, dibujamos un mapa del bloque. Este mapa incluía las características geográficas más prominentes así como la localización aproximada de todas las unidades de vivienda en los cuatro edificios. Entonces enumeramos todas las viviendas en la muestra e identificamos las unidades vacantes. Al mismo tiempo, revisamos la prensa hispana de Nueva York buscando referencias sobre la comunidad dominicana de Washington Heights y sus problemas socioeconómicos. Más aún, buscamos información sobre el trasfondo histórico de Washington Heights y el éxodo dominicano en las bibliotecas de la Universidad de la Ciudad de Nueva York y la Universidad de Columbia.

El trabajo de campo se dividió en tres equipos de investigación con dos miembros cada uno. ${ }^{8}$ Cada equipo era responsable de observar alrededor de 40 unidades de vivienda dentro del bloque. Dos de los investigadores eran cubanos residentes en Puerto Rico y el resto eran estudiantes dominicanos en la Universidad de la Ciudad de Nueva York, dos de ellos residentes en Washington Heights. El personal estuvo compuesto por tres mujeres y cuatro hombres, entre los 22 y los 36 años de edad. Tanto la composición étnica como la afiliación institucional del equipo facilitó el acceso a los residentes del bloque. Sin embargo, muchos residentes rehusaron participar en el estudio; algunos desconfiaban de los extraños y otros protegían fuentes de ingreso irregulares o ilf́citas, tales como asistencia pública y trabajos no informados al gobiemo. ${ }^{9}$

Inicialmente establecimos contacto visual con los residentes, sin hacer preguntas personales. Visitamos el bloque a distintas horas y en diferentes días de la semana para familiarizamos con el ritmo de la vida diaria del barrio y entrar en contacto con una mayor variedad de

8. Una de las asistentes de investigación tuvo que retirarse del estudio después del primer mes y fue reemplazada por otro estudiante.

9. Durante nuestro trabajo de campo, un juez de la ciudad de Nueva York sentenció a docenas de mujeres dominicanas por recibir asistencia pública fraudulentamente. La mayoría de las mujeres supuestamente eran jefas de familia solteras, desempleadas y con hijos pequeños. La advertencia del juez de que trataría a los dominicanos más duramente en casos futuros causó una pequeña conmoción en la comunidad dominicana y entre los activistas de los derechos civiles en la ciudad (New York Newsday 1993e). 
personas. Además, nos presentamos a los dueños y empleados de los comercios del área y tratamos de obtener su cooperación. En esta etapa, anotamos las características físicas de los residentes (tales como sexo, apariencia física y edad aproximada) mientras entraban y salían de sus apartamentos y caminaban por la acera. Cuando alguien nos miraba con curiosidad o nos preguntaba qué estábamos haciendo allí, le explicábamos que estábamos haciendo un estudio para la Universidad de la Ciudad de Nueva York sobre la comunidad dominicana de Washington Heights y su cultura. También distribuimos una carta oficial del Instituto de Estudios Dominicanos confirmando su endoso a nuestro proyecto. Después nos acercamos a los residentes para conversar informalmente y ganarnos su confianza.

Tras dos semanas de trabajo de campo, realizamos entrevistas intensivas con 37 residentes dominicanos dispuestos a cooperar con nosotros. Estas entrevistas formaban parte de conversaciones informales con miembros adultos de hogares dominicanos. También entrevistamos a portavoces de 59 hogares dominicanos sobre sus creencias y costumbres diarias. Anotamos sus respuestas en un formulario separado para cada hogar. Entonces procesamos los datos. Finalmente, estábamos listos para analizare interpretar los resultados. La próxima sección coloca nuestros hallazgos en una perspectiva geográfica e historica.

\section{El lugar de la investigación}

El contexto geográfico. Washington Heights ocupa una de las localizaciones más pintorescas en Manhattan. Al oeste se encuentran el Parque del Fuerte Tryon, el Río Hudson y el Parque Pallisades en Nueva Jersey: al norte están el Museo de los Cloisters y el vecindario de Inwood; al este, el Parque Highbridge, el Río Harlem y el Bronx; y al sur, Hamilton Heights y Harlem. La topografía accidentada y la localización periférica del área retrasaron su desarrollo urbano hasta entrado el siglo 20. El terreno era montañoso, rodeado por ríos en tres direcciones, y estaba relativamente lejos del centro de la ciudad (Protestant Council of Churches 1954; Lowenstein 1989).

Washington Heights fue el último enclave rural de Manhattan en urbanizarse a fines del siglo 19. Mientras Nueva York se expandía en 
otras direcciones, el norte de Manhattan se mantuvo como una comunidad agrícola relativamente aislada. Originalmente un área de extensas fincas y terrenos, Washington Heights se convirtio en un centro urbano para el comercio y el transporte, pero retuvo su carácter predominantemente residencial (Katznelson 1981; Abeles y Welnberg 1968). Durante las primeras tres décadas de este siglo, la comunidad se convirtió en un ejemplo notable de la marcada separación entre el lugar de residencia y el centro de trabajo de la gente. No es exagerado afirmar que Washington Heights es uno de los primeros suburbios modemos de los Estados Unidos.

Las fronteras precisas del vecindario siempre han sido fluídas. Aunque muchos estudios concuerdan que el núcleo de Washington Heights está situado entre las Calles 168 y 191, difieren en cuanto sus márgenes al norte y al sur. La localización del vecindario está claramente marcada por una súbita elevación del terreno al norte de la Calle 125 en Harlem, llegando a su ápice cerca de la Calle 135 (Lendt 1960). En la década de 1930, la Calle 135 aún formaba parte de Washington Heights, pero el borde sureño posteriormente se movió al norte hasta la Calle 155 y aún la 168. Este movimiento coincidió con la percepción de los residentes de Washington Heights como una comunidad blanca de clase media, distinta del Harlem negro y de clase baja. Por varias décadas, los propietarios de Washington Heights detuvieron la inmigración negra mediante prácticas de vivienda racialmente exclusivas (Elinson y Loewenstein 1963; Henriques 1984).

Trasfondo histórico. Washington Heights fue uno de los principales escenarios de la Revolución Americana y desempeñó un papel protagónico en la historia militar de los períodos colonial y republicano temprano. Entre los sucesos históricos más importantes del área se destaca la Batalla del Fuerte Washington en 1776. Varias estructuras físicas recuerdan eventos del pasado remoto y reciente de la nación norteamericana. La casa de retiro original de Alexander Hamilton y la Casa Dyckman se han preservado como monumentos históricos. En 1965, el Salón de Baile Audubon fue el escenario del asesinato del líder afro-americano Malcolm X y se convirtió en un lugar simbolico para la comunidad de Harlem. De esta manera, el norte de Manhattan adquirió un valor mítico basado en su gran número de lugares de interés histórico 388 
En 1920, un grupo de propietarios de Washington Heights publicó sus planes para desarrollar el área (Washington Heights Taxpayers Association 1920). En esa época, la Calle 157 era un centro residencial de clase alta. La sección norte del distrito era todavía "un bosque salvaje" con un terreno rocoso y árboles abandonados. Varias familias distinguidas habían construido casas elegantes, rodeadas de jardines, patios y árboles frondosos en los terrenos originales de la familia Audubon. Los visitantes viajaban en botes pequeños para bañarse en el Parque Pallisade al otro lado del Río Hudson. Los residentes del área propusieron que se completara la Avenida Riverside al norte de la Calle 155 para aumentar el valor comercial de la propiedad. Los residentes posteriormente perdieron el control del desarrollo del vecindario como resultado de políticas diseñadas por planificadores de la ciudad (Henriques 1984).

El vecindario sufrió cambios físicos y sociales abruptos durante las primeras tres décadas de este siglo. El mayor ímpetu para el desarrollo urbano fue la apertura de nuevas vías de transportación, especialmente el sistema del subway, que hizo al área más accesible desde el centro de Manhattan. En 1904, la Autopista del West Side llegó a Washington Heights. En 1908, la línea del subway IRT se extendió hasta el vecindario y se construyó una estación importante en la esquina de la Calle 181 y la Avenida Saint Nicholas. La línea del subway IND se completó en 1932 y el Puente George Washington se inauguró en 1935. $\mathrm{Al}$ integrarse al sistema de transportación urbano, Washington Heights se incorporó a la vertiginosa expansión de Nueva York.

El auge de la construcción comenzó en la década de 1910. La mayoría de los edificios de apartamentos se construyó en los años veinte y treinta. La estructura típica del área era un edificio de cinco o seis pisos. Muchos apartamentos eran relativamente baratos y atractivos para inquilinos de clase media. Los proyectos públicos y otras estructuras privadas acompañaron a la construcción de viviendas. En 1923, comenzo la construcción de la Escuela George Washington; el Centro Médico de Columbia-Presbyterian se completó en 1928. Para la década 
de 1930, Washington Heights era una pujante comunidad residencial en las afueras de Manhattan.

Estratificación social y segregación residencial. Durante la segunda mitad del siglo 19, Washington Heights era un suburbio exclusivo de Nueva York. A principios del siglo 20, la mayor parte de la población era blanca, anglosajona y protestante. Pero olas migratorias subsiguientes cambiaron la composición de la población. Después de la Segunda Guerra Mundial, muchos americanos irlandeses de segunda y tercera generación se mudaron al área. A fines de los años treinta, miles de judíos llegaron huyendo de la persecución nazi en Alemania y Austria. Los judíos se concentraron al oeste de la Avenida Broadway, mientras los irlandeses predominaron al este, cerca de la Avenida Amsterdam. Después de la Segunda Guerra Mundial, muchos negros y puertorriquenos se mudaron a Washington Heights. La mayoría de estos últimos inmigrantes se estableció en el sureste del vecindario, mientras que muchos residentes antiguos se desplazaron hacia el norte y el oeste (Lendt 1960; Katznelson 1981; Henriques 1984).

En los años cuarenta, la comunidad judía de Washington Heights era casi tan numerosa como la de Frankfurt. Muchos negocios judíos, así como sinagogas, periódicos y asociaciones judías se establecieron en el vecindario. Todavía en los años cincuenta, los judíos alemanes eran el grupo más grande en Washington Heights (Lowenstein 1989). Para esta época, Washington Heights tenía por lo menos 20 sinagogas (Protestant Council of Churches 1954). Hoy en día, muchas instituciones judías, como la Universidad Yeshlva y varias escuelas privadas, siguen funcionando en el vecindario. La sección nordeste del vecindario todavía se considera "territorio judío".

El rápido aumento de la población hispana y negra aceleró el éxodo de los residentes blancos, especialmente irlandeses y judíos, a los suburbios. Para 1960, los puertorriqueños eran el segundo grupo étnico más numeroso después de los judíos. Desde 1959. la Revolución Cubana llevó a miles de exiliados a Washington Heights. Después de 1965, los dominicanos llegaron en masa al barrio, atraídos por sus bajos alquileres, apartamentos espaciosos y facilidades de transportación. De esta manera, los hispanos reemplazaron a los blancos no hispanos como 390 
el mayor sector de la población en Washington Heights. Para 1970, Washington Heights tenía una de las proporciones más altas de residentesnacidos en el extranjero dentrode Manhattan, mayormente inmigrantes recientes del Caribe hispano (Alvelo et al. 1981). El barrio se había convertido en el punto principal de entrada para los inmigrantes dominicanos y cubanos en la ciudad.

Al mismo tiempo, Washington Heights se deterioro física y socialmente. El valor de la propiedad se redujo sustancialmente. Muchos edificios, especialmente en la sección sureste del vecindario, se dilapidaron. Durante los años sesenta, el vecindario reforzó su carácter proletario; la mayoría de los residentes trabajaba como operarios, trabajadores de servicio, artesanos y reparadores (Elison y Loewenstein 1963). Para los años setenta, Washington Heights era considerada un área de bajos ingresos con una tasa alta de criminalidad (Columbia Presbyterian Medical Center 1983). Originalmente una comunidad de clase alta, luego de clase media, Washington Heights se había convertido en una comunidad de clase trabajadora.

A pesar de los cambios, la Avenida Broadway siguió dividiendo al barrio social y étnicamente. Al oeste de Broadway se encontraban las áreas más prestigiosas, ocupadas principalmente por judíos de clase media, mientras las estructuras más deterioradas se situaban al este de Broadway. La mayoría de los blancos no hispanos vivía en el norte y el centro de Washington Heights; la mayoría de los afro-americanos y los puertorriqueños vivía en el sur. A medida que el área al sur de la Calle 140 se convertía en un "Cinturón Negro" (Henriques 1984), el este se hacía mayormente hispano. Los dominicanos ocuparon muchos edificios al este de Broadway, especialmente entre las Calles 155 y 173 , mientras los cubanos predominaron al norte del barrio, especialmente entre las Calles 174 y 187 (Alvelo et al. 1981). Así, la segregación étnica aún caracterizaba al vecindario, sólo que ahora los cubanos sustituían a los judíos y los dominicanos a los irlandeses.

Para 1980, más de la mitad de la población de Washington Heights era de origen hispano (New York City, Department of City Planning 1985). Los residentes judíos, junto con grupos más pequeños de blancos provenientes de Grecia, Rusia e Irlanda, se fueron aislando cada vez 
más, a medida que el barrío adquiŕa una atmosfera distintivamente hispana. ${ }^{10}$

Muchos empresarios hispanohablantes establecieron negocios en Washington Heights, deplazando a los propietarios de tiendas judías, ofreciendo nuevas oportunidades de empleo para los inmigrantes y promoviendo el uso del idioma español y la persistencia de la cultura hispana.

En los años cincuenta, muchos puertorriqueños eran dueños de bodegas, barberías y tiendas de dulces en el área. ${ }^{11}$

Más tarde, los cubanos y los dominicanos añadieron sus propias tiendas de discos, agencias de viaje, restaurantes, sastrerías y joyerías. La feligresía de la Iglesia Católica se hizo predominantemente hispana, primero puertorriqueña, luego cubana y después dominicana (Alvelo et al. 1981). Una parroquia recibió el nombre de Nuestra Señora de la Altagracia, la santa patrona de la República Dominicana. Dos escuelas públicas se llamaron Juan Pablo Duarte y Salomé Ureña, en honor de dos ilustres figuras de la historia dominicana. Indudablemente, las olas recientes de inmigrantes hispanos han transformado el paisaje cultural de Washington Heights.

\section{La situación actual.}

Aunque Washington Heights comienza oficialmente al norte de la Calle 155, los dominicanos han penetrado el área entre las Calles 125

10. Tanto los blancos como los negros no hispanos resintieron el influjo hispano. Un residente griego se refirió a sus vecinos latinos como "porquería" (en español), mientras que una mujer afro-americana se quejó de la siguiente manera: "Desafortunadamente vivo aquí. Soy una minoría, no hablo español, así que ellos (los latinos) no me hablan".

11. Para los años ochenta, los dominicanos er an dueños de la mayorá de las bodegas del alto Manhattan y de muchas al sur del Bronx. Los empresarios dominicanos han prosperado en el negocio de distribución de alimentos en Nueva York y Nueva Jersey, especialmente en los barrios urbanos del centro de la ciudad, abandonados por las grandes cadenas de supermercados norteamericanas (véase Duany 1987; Hispanic Market News 1993). 
y 134, también conocida como Hamilton Heights y popularmente identificada con Harlem. El sur del vecindario todavía es predominantemente una comunidad afro-americana. Los "bolsillos" negros se concentran alrededor de la Calle 145. Pero pocos negros y blancos no hispanos viven en el centro y el norte del vecindario.

En un bloque típico de Washington Heights, los comerciantes ambulantes venden chinas, maíz, flores, cintas musicales y bebidas de hielo (frío-frío). En días calurosos de verano, docenas de carritos de madera vendiendo frío-frío se sitúan en las principales intersecciones. Los nifos abren los hidrantes de bomberos y juegan con el agua en la calle. Los hombres usualmente hablan español, escuchan merengue, le dicen piropos a las muchachas, juegan domino, beben cerveza Presidente, juegan a la lotería, hablan de política dominicana y leen periódicos dominicanos como El Nacional, El Siglo y Listín Diario. Las mujeres pasean a sus hijos en coche, van de compras a la bodega o conversan con sus vecinas frente a los edificios. Los muchachos caminan a la escuela pública, se bañan en las piscinas del barrio o escuchan música norteamericana en inmensos tocacintas. Algunos peatones parecen mexicanos 0 centroamericanos por su acento, rasgos indígenas y pequeña estatura. Pero la mayoría de los residentes del área son inmigrantes dominicanos.

Con su fácil acceso al Puente George Washington, la Calle 181 es el centro del comercio y el transporte del barrio. El viejo túnel y los elevadores de la estación del subway están seriamente deteriorados y han sido objeto de protestas recientes por los residentes del área. ${ }^{12}$

Por las mañanas, la mayoría de los residentes toma el subway para trabajar en el centro de Manhattan y regresa por las tardes a Washington Heights. Otros residentes cogen la guagua para trabajar en las fábricas de Nueva Jersey, al otro lado del Hudson. Cerca de la estación del subway, varios negocios se especializan en enviar remesas a la República Dominicana, tales como el Banco Dominicano. Los taxis gitanos de

12. Durante nuestro trabajo de campo en Washington Heights, los estudiantes de la Escuela Intermedia Salomé Ureña exigieron que la Autoridad de Tránsito Metropolitano remodelara la estación. Algunos maestros, políticos y activistas comunitarios se unieron a los estudiantes (El Diario / La Prensa 1993e). 
la agencia dominicana Riverside, usualmente carros americanos, grandes y negros, constantemente cruzan las calles buscando clientes potenciales. Un puesto de periódicos en la esquina de la Calle 181 y Saint Nicholas ofrece diez periodicos dominicanos, que llegan diariamente de la Isla.

Numerosas cafeterías y restaurantes venden comida típica de la República Dominicana. La comida criolla incluye platos fuertes como mangú, carne guisada, salcocho, arroz con habichuelas, tostones, mondongo, cocido y cabeza de cerdo; bebidas como jugo de caña y batida de fruta; y platos menores como empanada de yuca, pastelillos de guayaba, yaniqueque, dulce de coco y pan dulce relleno. Las bodegas importan viandas y frutas tropicales desde plátanos hasta mamey. Un salón de belleza del área vende una gran variedad de productos dominicanos, como Lafier y Capilo. Los pequeños negocios para hacer llamadas telefónicas a la República Dominicana han proliferado en los últimos años. Un empresario dominicano de San Francisco de Macorís es dueño de 12 de estos locales y piensa abrir 50 más en el futuro cercano. Nuestro bloque tiene seis teléfonos públicos "porque hacen dinero", según un instalador telefónico con quien hablamos.

Aunque primordialmente residencial, nuestro bloque tiene diez. negocios en el primer piso de los edificios: dos bodegas, dos salones de belleza, dos barras, un restaurante, una panadería, una licorería y una ferretería. Siete de estos negocios son propiedad de dominicanos. El vecindario inmediato incluye otras bodegas, tiendas de ropa, botánicas, agencias de viaje, talleres de mecánica y otros pequeños negocios. Varios comerciantes se quejaron de la intensa competencia económica en un espacio tan reducido. "La gente no está comprando ahora porque no tiene dinero", dijo un vendedor de frío-frío. Además, el aumento en los alquileres amenaza con forzar a muchos comerciantes fuera del mercado y a la bancarrota. En nuestro bloque, los comerciantes pagan entre $\$ 1,700$ y 2,315 al mes por alquilar sus pequeños locales. La mayorfa de los empleados de los negocios dominicanos son dominicanos, aunque muchas tiendas también emplean a otros hispanos, especialmente ecuatorianos, mexicanos y salvadoreños. Muchos comerciantes despliegan su origen nacional poniendo música muy alta en la 
acera frente a sus negocios, usualmente merengue y salsa, ocasionalmente bachata y bolero. Algunos negocios son subsidiarias locales de empresas establecidas en la República Dominicana, como Nitín Bakery. Otros venden bebidas dominicanas como Cola Quisqueya, Refrescos Nacionales y Cerveza Presidente.

Los letreros comerciales confirman la fuerte presencia de inmigrantes de la región del Cibao, tales como Acogedor Cibao Supermarket, Cibao Vision Center, Cibao Meat Products y Hielo Cibao. Un inmigrante dominicano que sembró maíz y frijoles negros en la Avenida Broadway y la Calle 153 añoraba tener su "pequeño Cibao" en Washington Heights (The New York Times 1991d). Durante nuestro trabajo de campo, observamos cómo un muchacho caminaba por la acera con dos gallos de pelea, una escena común en el campo dominicano. Algunos dominicanos incluso se refieren al vecindario como "El Cibao" o "La Platanera" (Sepúlveda Castillo 1982).

Los clubes privados de la República Dominicana abundan en Washington Heights. Un estudio reciente de 18 asociaciones voluntarias encontró que servían a casi 20,000 dominicanos en Washington Heights (Sainz 1990). Docenas de asociaciones recreativas se basan en orígenes regionales, e incluso en pueblos específicos como Esperanza, Tamboril, Moca y Baní. Los miembros de estos clubes bailan merengue, juegan dominó y pelota, ven novelas en español, intercambian información sobre empleo y vivienda, y levantan fondos para enviar a su país de origen. Algunos clubes escogen a una reina de belleza y participan activamente en el Desfile Dominicano de la ciudad. La mayoría de los clubes se orienta primordialmente hacia la República Dominicana, aunque últimamente muchos se preocupan más por la comunidad inmigrante en Nueva York. Los clubes ayudan a recibir a los inmigrantes recién llegados y reafirmar las raíces culturales de los más establecidos (The New York Times 1991b).

A pesar de su gran población dominicana, Washington Heights es un vecindario multiétnico, multirracial y multilingüístico. Cerca de la Universidad de Yeshiva, en la Calle 186, judíos de clase media ocupan edificios recién renovados. "Algunos de estos edificios son muy lujosos", dijo el dueño cubano de una barra local. Los judíos hasídicos 
ocasionalmente caminan por el vecindario los sábados para asistir a la sinagoga. "Hay un choque social entre judíos y dominicanos", comentó una antigua residente dominicana del vecindario.

Mientras las relaciones domínico-judías han sido frecuentemente tensas, la mayor parte de los contactos dominicanos con otros grupos hispanos ha sido cordial. En varios edificios del área estudiada colgaban banderas puertorriqueñas de las ventanas, días antes del Desfile Puertorriqueño en julio. Este gesto simbolico sugiere que algunos residentes eran puertorriqueños y que los dominicanos también celebraban el desfile con sus amigos y vecinos puertorriqueños. También quedan algunos trazos físicos de una numerosa inmigración cubana en el barrio, especialmente negocios con nombres cubanos, como Restaurante Caridad, Cafetería El Mambí, Havana Bar y Restaurante Sagua. Además, nuestro bloque tenía comerciantes e inquilinos griegos, chinos, italianos, nicaragüenses, peruanos, afro-americanos y miembros de otros grupos étnicos.

Varios eventos noticiosos ocurrieron durante nuestra estadía en Washington Heights. Al comenzar nuestro trabajo de campo, la policía confisco 19 carros con estereos demasiado altos en las calles de Washington Heights (New York Daily News 1993). Días después, tres bodegueros dominicanos fueron arrestados por sobomar a la policía y vender apuestas en la lotería ilegal ("la bolita"). La policía también sospechaba que los bodegueros estaban contrabandeando ron dominicano en los Estados Unidos (El Diario/La Prensa 1993g; Noticias del Mundo 1993c).

Por otra parte, un súper dominicano fue asesinado en la Calle 136 después de comprar cerveza y cigarrillos en una bodega cercana (El Diario/La Prensa 1993a). Un adolescente dominicano murió cerca de la Calle 137 y la Avenida Audubon. Amigos y parientes improvisaron un altar en una esquina, con una foto del muchacho y un letrero que decía "Vaya con Dios", junto con velas y flores. En otro incidente, dos jóvenes hispanos fueron abaleados en una pelea callejera; uno de ellos fue herido de muerte (El Diario/La Prensa 1993b). Finalmente, un adolescente trató de violar y asesinar a su madrastra puertorriqueña en su apartamento, y tres jovenes hispanos asaltaron sexualmente a una muchacha en una 396 
piscina pública de Washington Heights (El Diario/La Prensa 1993i; New York Newsday 1993a). En suma, los medios de comunicacion masiva tienden a caracterizar a la comunidad dominicana de Washington Heights como violenta y desordenada. Como señaló Manuel, uno de nuestros informantes, "Es una discriminación total lo que hay en las noticias contra los dominicanos".

Un año después de la muerte de Kiko García, Washington Heights se convirtió nuevamente en escenario de violencia callejera. Primero la policía realizó una redada en el mismo edificio donde mataron a García y arresto a 13 personas por posesión de drogas y armas de fuego ilegales (Noticias del Mundo 1993b). Más tarde, una patrulla de la polića accidentalmente choco y mató a un muchacho puertorriqueño que trabajaba en una bodega del vecindario. En señal de protesta, varias gangas de jóvenes dominicanos voltearonlatones de basura, les echaron alcohol y los quemaron. Cuando un camión de bomberos respondió a una llamada de emergencia, dos dominicanos tiraron una bomba Molotov dentro del camión e hirieron a tres bomberos (New York Newsday 1993b, 1993d). Al final de nuestro trabajo de campo, varios desconocidos lanzaron botellas a dos oficiales de la policía desde el mismo edificio donde murio García. La policía respondió cercando el bloque durante 12 horas, pero no encontro a los culpables (Noticias del Mundo 1993a). Como advirtió un activista comunitario.

El ataque contra los bomberos es solamente un indicio más de hasta dónde la frustración y la alienación están llevando a nuestros jóvenes[... ] la colectividad de gente se siente abusada por un grupo que se supone los proteja. En Washington Heights, la mayoría de la gente le ha perdido el respeto y confianza a la policí; lo que le tiene es miedo y resentimiento (El Diario/La Prensa 1993j). ${ }^{13}$

13. Según una de mis asistentes de investigación, los inmigrantes dominicanos han desarrollado una imagen negativa de la policía como resultado de sus experiencias en la República Dominicana. Muchos recuerdan los abusos de la policía secreta de Trujillo y las tácticas represivas de Balaguer. Desafortunadamente, el contacto de muchos inmigrantes con los policias norteamericanos en Nueva York ha reforzado su percepción despectiva. 
Sorprendentemente, las constantes tensiones entre los residentes y la policía no alteraron el ritmo de la vida cotidiana en el bloque bajo estudio. Más bien, tal antagonismo forma parte del quehacer diario de la comunidad dominicana.

\section{El bloque.}

Sólo uno de los edificios en la muestra tenía acceso controlado, lo cual representaba una mayor seguridad para los residentes. Como resultado, este edificio estaba en mejores condiciones que los otros tres, con poco graffiti en las puertas y ventanas. Originalmente construido en la década de 1910, el edificio tenía una fachada de ladrillo, una puerta de nogal en el elevador, ventanas de cristal ahumado, paredes de mármol blanco y un techo alto decorado. Tales características arquitectónicas sugieren que el edificio fue diseñado para inquilinos de clase media.

Los otros edificios estaban seriamente deteriorados porque, según algunos inquilinos, los dueños no los reparaban. Tres de los súpers eran dominicanos; uno era peruano. Varios informantes creían que los dueños eran judíos, puertorriqueños o irlandeses. Un comerciante cubano pensaba que un judfo era dueño de todo el bloque. "¿Ustedes son los dueños del edificio?--nos preguntó una inquilina afro-americana--. Yo nunca los he visto". Las relaciones entre los dueños y los inquilinos de los apartamentos tendran a ser distantes y tensas.

Las puertas de madera en la entrada de uno de los edificios estaban rotas, así como muchas ventanas de cristal en las escaleras. El techo del vestíbulo necesitaba pintarse y la azotea estaba llena de graffiti. La puerta del elevador estaba rayada y tenía el cristal roto. Cuando Susan se mudó al edificio hace cinco años, estaba en buenas condiciones, pero ahora los vagabundos se orinaban constantemente y ensuciaban los pasillos. Una mujer blanca no hispana le echó la culpa a los dominicanos de vandalizar el vecindario.

La fachada y el pasillo del edificio se pintó recientemente para cubrir el graffiti y el sucio. Durante la última semana de nuestro trabajo de campo, se instalaron rejas y paneles de plástico en la puerta de 
entrada. Aunque el asistente del súper limpiaba los pisos durante la semana, estaban sucios de nuevo los lunes. Tres apartamentos estaban cerrados por orden policial y sus ocupantes fueron desalojados porque no pagaban el alquiler. Uno de estos apartamentos estaba en proceso de renovación y sería alquilado por $\$ 650$ al mes. Otro apartamento, aparentemente vacío, servía como punto de distribución de drogas. Personas ajenas a la comunidad entraban y salían constantemente de este apartamento, después de realizar sus transacciones ilegales. Los residentes estaban al tanto de la situación pero temían denunciarla a la policía.

La mayoría de los inquilinos mantenía las puertas de sus apartamentos herméticamente cerradas. Pocos salían a conversar al pasillo, excepto por varios inmigrantes dominicanos recién llegados. Algunas personas se paraban frente a sus edificios a socializar y ver la gente pasar. La estructura física de los edificios no fomentaba la interacción social en los espacios públicos y abiertos a los que están acostumbrados los dominicanos en su país de origen. El bloque carecía de un lugar de reunión común, salvo quizás las bodegas. La mayor parte de la vida cotidiana de los inquilinos transcurría a puerta cerrada, en la privacía de sus apartamentos, por miedo al crimen o la deportación por las autoridades de inmigracion. "Las relaciones de vecinos no existen aquí como en Santo Domingo--dijo Freddy--. Los vecinos son anglosajones y en cuatro años no hemos hablado". Sólo en una ocasión vimos niños jugando en los pasillos.

Sin embargo, algunos vecinos han logrado crear una pequeña comunidad, marcada por un intercambio frecuente de favores, ayuda mutua y apoyo emocional. Algunos inquilinos cuidaban a los niños de sus vecinos, les llevaban la basura al sótano, compartían comidas étnicas o les traían plátanos del mercado. Cada edificio tenía varias redes principales de interacción social, dándole al lugar un ambiente de pequeño pueblo auto-suficiente.

14. Algunos residentes desconfiaban de nuestros motivos y tenía miedo de abriri sus puertas porque varios ladrones había robado en el vecindario, haciéndose pasar por oficiales de la policía o empleados de reparación eléctrica. Una mujer había sido violada recientemente en el área. 
La mayoria de los inmigrantes mantenía sus tradiciones culturales en casa. Algunos inquilinos ponían letreros en español en las puertas de sus apartamentos, como para anunciar su origen nacional, especialmente con mensajes religiosos como "Jesús única esperanza", "Cristo cambiará tu vida" y "Construyamos la paz con Cristo". Dentro de sus hogares, muchos dominicanos colgaban litografías religiosas en las paredes, como el Sagrado Corazón de Jesús y la Ultima Cena. Mercedes tenía un letrero citando al Libro de Génesis: "Este lugar no es otra cosa que casa de Dios y puerta de cielo".

Algunas familias tenían calendarios en español con una imagen de la Virgen Maria, adquirida en una de las bodegas locales. Otras familias colgaban una bandera o un escudo de la República Dominicana en un lugar visible de la sala. Muchos hogares dominicanos tenían muebles cubiertos de plástico, manteles de plástico y flores de plástico como su decoración principal. Varios hogares desplegaban las muñecas de cerámica sin cara típicas de la República Dominicana, así como platos pintados con colores brillantes con temas folklóricos de su país. usualmente un paisaje rural, una escena campesina, la Catedral de Santo Domingo o una playa tropical. Tales objetos mantenían una presencia grafica de la República Dominicana en Washington Heights.

Muchos hogares y negocios dominicanos tenían pequeños nichos con imágenes de santos católicos y la Virgen María en una esquina del salón principal o un cuarto privado. Estos humildes altares usualmente estaban rodeados de flores, velas prendidas, comida, vasos de agua fresca, vino y otras bebidas. Aunque las figuras más populares eran la Virgen de Altagracia y San Lázaro, los altares representaban una gran variedad de imágenes religiosas: Santa Clara, San Antonio de Padua, Santa Bárbara, el Santo Niño de Atocha, el Sagrado Corazon, la Sagrada Familia y la Virgen de Fátima, entre otras. Al igual que otros católicos hispanos, los dominicanos creen que los santos los protegen de los infortunios y los ayudan a progresar económicamente. Una mujer dominicana llevaba un collar con un medallon de la Virgen de Altagracia porque según explicó, "cuando estás fuera de tu paŕs, necesitas protección. Y también tu pars". Incluso una norteamericana de origen irlandés había arreglado un altar a la manera dominicana con la ayuda de una 
amiga inmigrante. En suma, la tradicional devoción a los santos y la Virgen sigue siendo muy fuerte entre los dominicanos de Washington Heights.

\section{Resultados}

Características socioeconomicas. El Cuadro 2 describe las principales características socioeconómicas de la muestra. Primero, la mayoría de los inmigrantes dominicanos nacio en los grandes centros urbanos de la República Dominicana: Santo Domingo, Santiago, San Pedro de Macorís, La Romana, San Francisco de Macorís y Puerto Plata. La ciudad de origen más común era San Francisco de Macorrs, ${ }^{15}$ seguida de Santiago y Santo Domingo. Segundo, la mayoría de las personas mayores de 25 años tenía por lo menos una educación elemental; un 40 por ciento tenía entre 9 y 12 años de escolaridad. Tercero, casi la mitad de los empleados eran trabajadores de servicio no diestros, seguidos por operarios y obreros. Las ocupaciones más frecuentes eran limpiadores, conserjes, domésticas, mozos, cocineros, parqueadores, taxistas, guardias de seguridad, operarios de fábrica, costureras y mecánicos. Cuarto, más de la mitad de los trabajadores estaba empleada en la rama de los servicios, seguida del comercio y la manufactura. Finalmente, la muestra tenía una baja proporción de parejas casadas y una alta proporción de hogares encabezados por mujeres, así como familias extendidas y personas solas.

Nuestros datos confirman varias tendencias observadas en estudios anteriores de la comunidad dominicana de Washington Heights, y también sugieren nuevas tendencias. Como era de esperarse, la gran mayoría de los inmigrantes dominicanos nació en los principales centros urbanos, se concentra en los sectores intermedios del sistema educativo y se origina en los estratos medios de la sociedad emisora. Además, el proceso de migración y asentamiento en un país extranjero representa una ruptura en la estructura tradicional de muchas familias

15. Como apuntó un informante, San Francisco de macorís se asocia popularmente con prósperos dominican-yorks, que han hecho su fortuna traficando drogas (véase The New York Times 1991c). Sin embargo, la mayoría de los residentes en nuestro bloque trabaja en ocupaciones legales, aunque frecuentemente informales. 
dominicanas. La separación matrimonial, temporal o permanente, es un rasgo común de los hogares migrantes.

CUADRO 2

CARACTERISTICA SOCIOECONOMICA DE LA MUESTRA

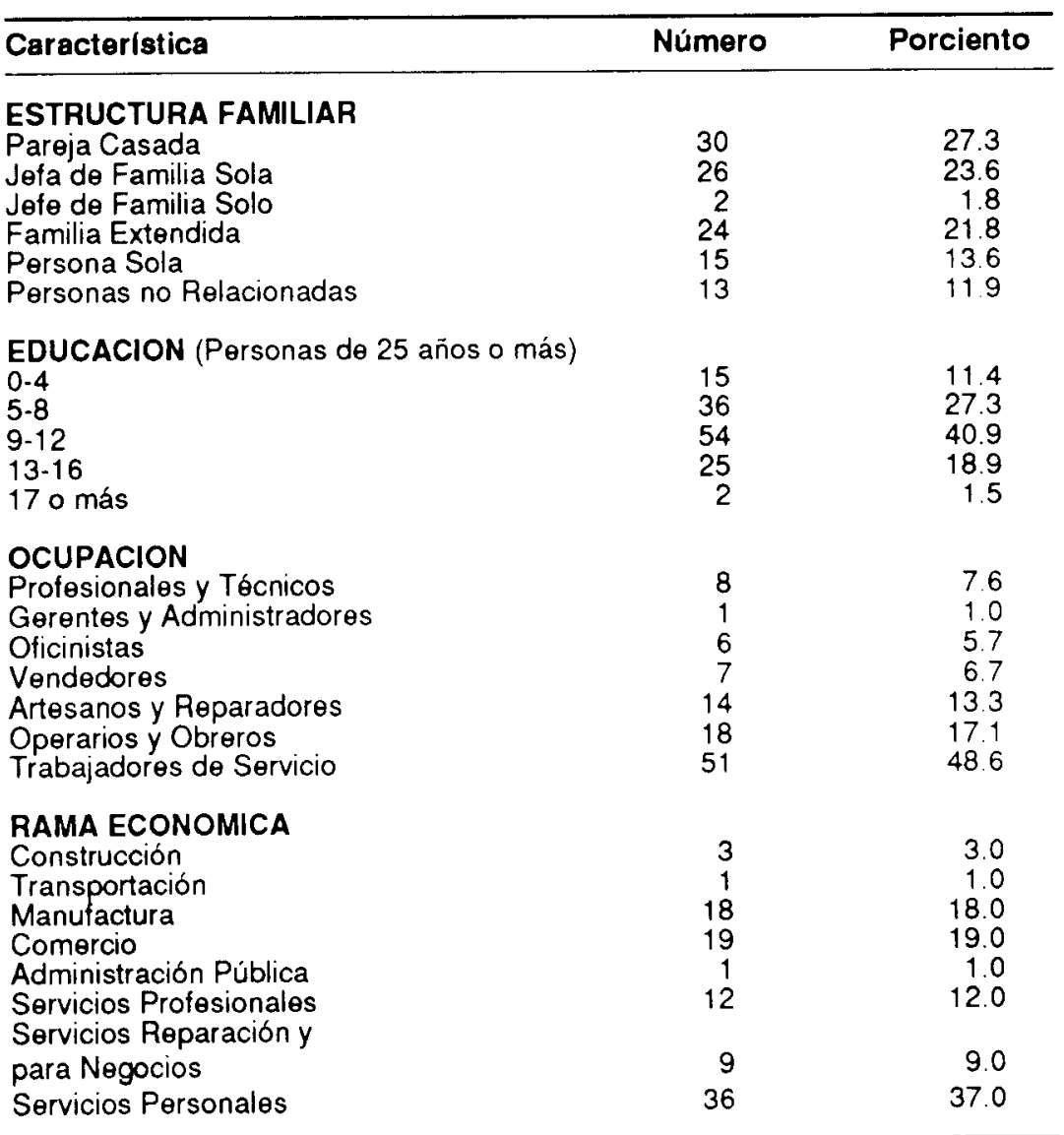

Nota: $N=352$. Falta Información para 13 a 66 casos dependiendo de la variable. 
Por otro lado, la proporción de jefas de familia solas fue mucho menor en nuestra muestra que en otros estudios. En muchos casos, pudimos identificar mujeres cuyos maridos estaban presentes en el hogar pero escondidos a las autoridades del gobiemo. Las observaciones repetidas de muchas familias dominicanas confirmaron la presencia de un hombre adulto no informado al principio del estudio. Sin embargo, la mayoría de las jefas de familia era el principal sostén económico de sus hogares. En este contexto, la autoridad tradicional de los hombres en el hogar se reduce significativamente.

Quizás más importante, los datos sugieren que los inmigrantes dominicanos no se están moviendo masivamente hacia arriba en la escala ocupacional, convirtiéndose en empresarios o creando una economía de enclave diversificada. Por el contrario, muchos trabajadores dominicanos se han desplazado de la manufactura liviana, especialmente la industria del vestido, hacia la rama de los servicios de bajos salarios. A grandes rasgos, este movimiento dentro del mercado laboral ha sido lateral $o$ descendente. Algunos entrevistados han perdido empleos relativamente bien pagados como mecánicos, costureras o carpinteros como resultado de la recesión económica de la ciudad. Otros apenan están sobreviviendo, vendiendo comida en la calle o manejando taxis gitanos. En suma, la reestructuración económica de Nueva York ha perjudicado seriamente a los dominicanos de Washington Heights.

El Cúadro 3 documenta aún más la condición marginal de la mayoría de los residentes en el mercado laboral. Sólo una tercera parte estaba empleada, incluyendo a muchos en trabajos inestables e irregulares como el cuidado informal de niños o la cocina desde el hogar. Alrededor del 15 por ciento estaba oficialmente desempleado; muchos recibían beneficios del gobierno tales como asistencia pública y compensación por desempleo. El resto de los residentes se encontraba fuera de la fuerza laboral, incluyendo a las personas retiradas e incapacitadas. Pocas mujeres informaron ser amas de casas como ocupación principal, pero la mayoría de los jovenes eran estudiantes. La proporción de residentes empleados a no empleados era de uno a tres. Por lo tanto, la identidad transnacional de los dominicanos de Washington Heights debe examinarse en el contexto de una intensa deprivación socioeconómica. 
CUADRO 3

CONDICION DE EMPLEO DE LOS RESIDENTES

\begin{tabular}{lcr}
\hline Ocupación & Número & Porciento \\
\hline Empleado & 105 & 37.4 \\
Desempleado & 43 & 15.3 \\
Retirado & 20 & 7.1 \\
Incapacitado & 4 & 1.4 \\
Ama de Casa & 18 & 6.4 \\
Estudiante & 91 & 32.4 \\
\hline Total & 281 & 100.0 \\
\hline
\end{tabular}

En busca de una vida mejor.

Los dominicanos expresan sus valores y prácticas culturales desde sus motivos para emigrar. Nuestras entrevistas confirmaron que la mayoría de los dominicanos se mudó a los Estados Unidos "buscando mejor vida", como dicen típicamente. La concepción de los migrantes de una vida mejor se basaba en el progreso material, reflejado en mejores salarios, mayores oportunidades de empleo y estándares de vida superiores. "Mis padres vinieron para tener más dinero, para progresar", dijo Joannie. "Vine porque estaba sola con mis dos hijos -dijo Ana Sofía- y lo que ganaba allá no me alcanzaba para nada". "Vine por la crisis económica en la República Dominicana", señaló Freddy. "En Santo Domingo estaba pasando hambre y tenía deseos de progresar", añadió otro residente. Un comerciante del área comento: "Quienes hemos venido a este país casi siempre esperamos acumular algo de dinero para retiramos" en la República Dominicana. Y Antonio señalo: "El dólar le gusta a cualquiera". Como argumentaré más adelante, los dominicanos articulan una paradoja entre sus tradiciones culturales y el progreso material, entre el deseo de mantener su identidad y ascender económicamente.

Muchos informantes mencionaron razones no económicas para 
emigrar, tales como "Vine buscando una mejor suerte para mis hijos", "Necesitaba descubrir nuevos horizontes", "Me gusta explorar", "Para buscar mejor futuro" o "Tuvimos que venir para evitar problemas familiares". Algunos entrevistados se mudaron a los Estados Unidos para escapar de la persecución política después de la Guerra Civil de 1965 en la República Dominicana. Un tema recurrente en nuestras entrevistas fue el de la migración como una búsqueda constante, en que la gente busca -y a veces encuentra- experiencias recompensantes al final de una lucha dolorosa por sobrevivir y mejorar. Aunque la migración tiene una lógica económica inconfundible, los lazos sociales invariablemente facilitaron el asentamiento de los dominicanos en Washington Heights.

Una imagen central en el discurso de los migrantes es la familia, definida ampliamente para incluir a primos, tíos y hasta compadres y padrinos. Las redes de parentesco desempeñaron un papel protagonico en la decisión de mudarse a los Estados Unidos. Muchos jovenes, especialmente las mujeres, vinieron porque "me trajeron" o "me pidieron", usualmente sus padres, esposos o hijos, pero a veces parientes cercanos. "Toda mi familia estaba aquí- explicó Rocío--. Así que tuve que venir". "He trafdo 22 familiares a este país en los últimos 25 años", senal6 orgullosamente Daniel.

Los estudiosos han anotado la fortaleza de los lazos familiares entre los dominicanos, que tienden a visualizar el proceso migratorio como una "cadena" geográficamente dispersa de parientes (Garrison y Weiss 1979). Lo que requiere mayor énfasis es que los mismos orígenes de la experiencia migratoria, así como el asentamiento en el país receptor, se encuentran en la familia extendida de los migrantes. Más aún, la fuerte ideología familiar de los migrantes dominicanos significa que gran parte de su identidad étnica y su cultura popular se preserva en la esfera privada del hogar.

La mayoría de los entrevistados dijo que había entrado legalmente a los Estados Unidos, usualmente con una visa de residente obtenida a través de un pariente cercano. Este hallazgo puede reflejar nuestra decisión de entrevistar personas que se sintieran cómodas con nosotros, 
y por lo tanto muchos inmigrantes indocumentados no participaran en las entrevistas. Aún así, algunos dominicanos reconocieron haber llegado con una visa de turista ("de paseo") y quedarse más allá del tiempo estipulado en la visa. La mayoría de estos individuos había regularizado su situación legal en los Estados Unidos, a veces casándose con un ciudadano americano. Sólo un entrevistado dijo que vino ilegalmente, usando los documentos de otra persona. Un entrevistado dijo que estaba "poniendo sus papeles en orden" para hacerse residente.

El patrón más común fue el que emigrara un miembro de la familia primero, usualmente el marido, que traería al resto de la familia una vez obtuviera la residencia permanente en los Estados Unidos. Antonio recuenta su experiencia:

Llegué solo. Poco a poco fui trayendo a mis hijos, de adultos. La cosa no es fácil para los niños acá. Vine con visa de paseo. La gran logia me ayudó a venir aquí. Después me casé con una puertorriqueña y me hice ciudadano americano.

Daniel tambiên fue el primero de su familia en emigrar:

Llegué como marino mercante. No tenía visa. Hice la residencia fácil. Busqué un abogado que me cobró 1,500 dólares por resolverme la situación. Después de cinco años me hice ciudadano y traje a la familia, primero a la esposa.

La historia de Esperanza es túpica de muchas mujeres dominicanas que siguieron a sus maridos emigrantes:

Mi esposo me pidió con los hijos. El vino en 1963 y reconoció a sus hijos. Vine con seis muchachos por Puerto Rico. Vine directamente a Nueva York, donde mi esposo nos encontro. Pan American me atendió muy bien. Todos teníamos visas del consulado americano en Santo Domingo.

De manera parecida, Joannie nos conto:

Primero vino mi mamá, después mi padrastro desde Puerto 406 
Rico. Después vinieron los hijos de Santo Domingo. Nuestros padres nos pidieron.

El proceso de reunificación familiar, sin embargo, puede durar décadas por los obstáculos legales y financieros de auspiciar la migración de familiares de la República Dominicana. Debido a que la mitad de los dominicanos en nuestro bloque inmigró a los Estados Unidos después de 1979, la mayoría aún tenía parientes en su país de origen. Algunos se quejaron de que las regulaciones de visa en los Estados Unidos dificultan el traer a toda la familia de la Isla.

\section{La familia y la patria.}

¿Por qué se establecieron los dominicanos en Washington Heights? De nuevo, las razones familiares predominaron entre nuestros entrevistados. Varios dijeron que vinieron porque tenían parientes en el vecindario, que les proveyeron albergue, comida y orientación al llegar a Nueva York. La mayoría de los informantes - 30 de 36-tenía parientes cercanos en Washington Heights, mayormente hijos, hermanos y primos. El segundo destino más popular para los inmigrantes recién llegados era el Bronx, donde la población dominicana ha aumentado rápidamente en la última década (New York City, Department of City Planning 1992).

Muchos inmigrantes también tenían amigos cercanos en Washington Heights, frecuentemente del mismo barrio de su pueblo en la República Dominicana. "Conocía gente aquí que podía cuidar a mis hijos", explicó Noelia. "Queŕa quedarme con mis gentes", afirmó Rosa. "Aquí puedo relacionarme con mi gente", reiteró Juana. La atmósfera dominicana del barrio, con sus comercios y oportunidades de empleo para hispanos, fue una atracción clave para los inmigrantes. El deseo de mantener su identidad cultural orientó a muchos dominicanos hacia Washington Heights.

Unos cuantos informantes mencionaron razones más pragmáticas para relocalizarse en Washington Heights, tales como "me queda todo cerca" 0 "no puedo pagar un alquiler más al to". ${ }^{16}$ Pero el principal imán 
del vecindario era su densa comunidad dominicana, con su amplia variedad de apoyos informales, instituciones sociales y servicios comerciales. En Washington Heights, los hombres solteros pueden comer comida criolla en restaurantes baratos y beber en compañía de muchachas dominicanas. Una señora mayor mencionó que se mudó al barrio porque aquí podía encontrar cualquier producto dominicano de su necesidad, en especial en las botánicas, porque yo soy una mujer enferma y tengo que hacer tés de raf́ces de mi país. El maguel, por ejemplo, es muy difícil de encontrar en otros lugares que no sea aquí. Por eso yo me siento como si estuviera en Santo Domingo.

También conocimos a un hombre que vendía "botellas", una medicina popular hecha con raíces, tallos y hojas de varias plantas tropicales. La medicina supuestamente ayuda a purificar la sangre, limpiar los riñones y fortalecer el apetito sexual. En las calles y las casas de Washington Heights, el folklore dominicano se mantiene vivo.

El Cuadro 4 muestra que los dominicanos están moderadamente encapsulados en su comunidad. La inmensa mayoría de los entrevistados tenía parientes en la ciudad de Nueva York, especialmente en Washington Heights y el Bronx. La mayoría encontró su último empleo a través de amigos y parientes.

Casi la mitad de los entrevistados trabajaba con otros dominicanos. aunque pocos tenían patronos dominicanos. Tres de cada cuatro entrevistados tenían amigos no dominicanos, especialmente puertorriqueños y otros hispanos. Sin embargo, pocos tenían amigos no hispanos, tales como afro-americanos y blancos no hispanos. Finalmente, la mayoría de los dominicanos no pertenecía a asociaciones étnicas. En resumen, la comunidad dominicana de Washington Heights está relativamente abierta a otros grupos étnicos, especialmente los hispanos, a pesar de su alto grado de segregación residencial.

16. Los alquileres locales variaban de $\$ 250$ por un apartamento de un cuarto a $\$ 650$ por un apartamento renovado de dos cuartos. Estos precios eran relativamente bajos para Manhattan. 
CUADRO 4

RELACIONES SOCIALES DE LOS INMIGRANTES DOMINICANOS

Relación Social ( $N=37)$

Porciento

Tiene parientes en la ciudad de N. York

97.3

Tiene parientes en Washington Heights

Tiene amigos hispanos

Tiene amigos no dominicanos

Encontró último empleo mediante amigos o parientes

Trabaja con otros dominicanos

Tiene parientes en el Bronx

Trabaja para un dominicano

Aunque la mayoría de los inmigrantes no pertenecía a una asociación voluntaria, los entrevistados mencionaron varias razones para afiliarse a clubes y otras organizaciones dominicanas. Joannie afirmo:

Me gustaba cantar y bailar. Así que me hice miembro de Alianza Dominicana. Después dejé de ir porque era de noche y a mi mamá no le gustaba.

Dersis participaba activamente en varias organizaciones dominicanas, especialmente en Alianza, porque "estaba muy cerca de la comunidad. Pero las dejé porque tenía tres hijos que atender". Otros entrevistados dijeron que pertenecían a clubes dominicanos porque querían "tener más relaciones con sus gentes". "Quería tener amigos de mi pueblo", dijo un miembro del Club Puertoplateño. "Era socio del club Gregorio Luperón en Puerto Plata -señaló José- y como la mayoría de nosotros estamos aquí, pues formamos el club". Algunos informantes pertenecían a instituciones religiosas dominicanas, como una iglesia evangélica cercana, porque compartían "un interés en Jesús Cristo" y "el sentido de camaradería". 
La mayoria de los entrevistados ( 31 de 37) se sentía dominicana, no norteamericana y ni siquiera domínico-americana. Al describir a su país de origen, muchos inmigrantes usaban términos emocionales como "mi patria", "mi tierra", "mi pars" y "la madre tierra". Los informantes constantemente subrayaban el adjetivo posesivo ("mi") al referirse a la República Dominicana, pero no a los Estados Unidos, al que usualmente llamaban "este país". Tal diferencia semántica típicamente denotaba una distancia emocional y una actitud critica frente a la sociedad receptora. Según un informante, "en este país la vida es más corta porque hay mucho estrés". Antonio añadio: "Este es un país comercial y es muy difícil hacer amigos aqur".

Por otro lado, Estela señal6: "Nací allá y me gusta mi tierra". Antonio reiteró el tema principal:

Esa es mi patria. Alli naci. Tuve a mis hijos allí. No puedo olvidar mi pedacito de tierra. Pero le agradezco a este país.

La mayoría de los inmigrantes dominicanos probablemente estaría de acuerdo con la apreciación de Dersis: "uno se sigue sintiendo del país donde nació". Noelia explicó este fenómeno señalando: "a la patria uno le tiene amor como a la familia". "Eso se lleva en la sangre", afirmo un tercer informante. Sólo dos inmigrantes se identificaron como americanos: "Me siento casi americana", dijo Paula. "Me siento de aquí ya porque llevo 14 años aqur", dijo Marra. Pero "es difícil sentirse americano -según Daniel- porque hay mucha discriminación contra los hispanos. En el trabajo ni siquiera nos dejan hablarespañol". Finalmente, muchos residentes de largo tiempo como Octavina están desarrollando una identidad ambivalente:

Mientras estoy aquí, me siento americana. Cuando voy a mi país, me siento dominicana, aunque no tengo derechos allá. Soy leal a esta bandera, pero quiero a mi pars.

¿Cómo se distinguen los dominicanos de otros grupos étnicos en Nueva York, tales como los puertorriqueños y otros hispanos? Esta fue una de las preguntas más difíciles de contestar para nuestros informan- 
tes, quienes mostraron poco consenso sobre el núcleo común de la identidad dominicana. ${ }^{17} \mathrm{La}$ característica citada más frecuentemente fue el acento dominicano al hablar español, seguida de referencias estándares a la música de merengue y la comida criolla. "El que no come arroz ni habichuelas ni plátano, no es dominicano", declaró una mujer. Otro informante dijo que prefería un plato de mangú con salchichón a ser rico.

Algunos informantes señalaron características psicológicas distintivas de los dominicanos. Octavina opino: "da gusto ver a los dominicanos trabajar"; pero otros pensaban que los dominicanos no eran muy trabajadores. Algunas personas creían que la comunidad dominicana era unida y armoniosa, mientras que Dersis opino que los dominicanos "sólo se juntan pa' fiestar". Según Rafael, "los dominicanos no tienen compañerismo, se matan entre ellos mismos". Las entrevistas generaron una larga lista de adjetivos para describir a los dominicanos, algunos de ellos incongruentes, tales como alegres, escandalosos, alborotados, sociables, orgullosos, ambiciosos, presumidos, difíciles, complicados, limpios, leales, decentes, respetuosos, patrioticos, agresivos y no conformistas. A pesar de algunas imágenes negativas, el autorretrato de los dominicanos era predominantemente favorable.

La preocupación por el narcotráfico surgió espontáneamente durante las entrevistas. Joannie señalo: "muchos dominicanos no piensan en ayudar al país; vienen a vender drogas y hacer cosas malas". " ¿Qué vergüenza ser dominicanos!", confesó Mercedes, refiriéndose a los recientes disturbios policiales en el vecindario:

Nosotros no valemos nada. El muchacho que mataron era un delincuente. Uno sale del país a buscar mejoría y lo que encuentra es vergüenza ¡Ay, tanta hambre que pasamos en Santo Domingo!

Otra entrevistada dramatizó la situación: "los dominicanos se han echado a perder; vienen como chivos sin ley". "A mí me da hasta

17. A los informantes dominicanos de Sainz (1990)también se les hizo difícil identificar diferencias y semejanzas entre hispanos, aunque la mayoría de ellos rechazó el término "hispano" para definir su propia identidad étnica. 
vergüenza ser dominicano -dijo otro informante-por la mala reputación que tenemos". Según Antonio, "la comunidad dominicana es un montón de garbage [basural) y toda la gente joven o vende drogas o mata a la gente por dinero". Muchos inmigrantes han intemalizado el estigma difundido por los medios de comunicación masiva.

Cultura, nacionalidad y ciudadanía. A pesar de todo, la mayoría de los entrevistados se mantiene apegada a su cultura de origen. El Cuadro 5 muestra cómo los hogares dominicanos se comportan en varios índices de persistencia cultural. Los datos sugieren que los inmigrantes retienen un fuerte apego a sus patrones tradicionales de comida, idioma, consumo y religión. Los hábitos de ver televisión, escuchar la radio y escuchar música mostraban menos apego a la cultura hispánica y dominicana. Más aún, la mayoría de los miembros de los hogares no leía principalmente en español, ni celebraba eventos públicos de origen dominicano. ${ }^{18}$ La mayoría de los inmigrantes conserva muchas creencias y costumbres dominicanas, aunque cada vez más mezcladas con la cultura norteamericana. En este sentido, los dominicanos han creado una identidad transnacional en Nueva York.

El proceso de americanización ha avanzado especialmente entre los dominicanos de la segunda generación, los nacidos y criados en los Estados Unidos. Este último grupo constituye alrededor del 39 por ciento de la población dominicana de la muestra. Los adolescentes dominicanos frecuentemente hablaban inglés entre ellos, veían programas de la televisión norteamericana, escuchaban música rap, usaban mahones grandes y seguían los estilos hip hop de sus contemporáneos afro-americanos y puertorriqueños en Nueva York. ${ }^{19}$ Según un

18. El principal evento comunitario, el Desfile Dominicano de Nueva York, ha estado plagado de problemas organizativos causados por rivalidades personales y políticas. estos problemas han erosionado la participación popular en el desfile (véase el Diario / La Prensa 1993c: Village Voice 1988). En 1990, alrededor de 250,000 dominicanos participaron en el Desfile Dominicano de Manhattan. en 1993, se esperaba que asistieran 50,000 a la Parada Dominicana en el Bronx (The New York Times 1990: El Diario / La Prensa 1993c).

19. Según Juan Flores (1988), la cultura hip hop tiene tres componentes esenciales: el rap, el breakdancing y el graffiti. El hip hop surgió entre los jóvenes afro-americanos 
inmigrante dominicano de primera generación, los jovenes son los que se arraigan y se quedan aquí, pero los que vinieron adultos nunca se adaptan por completo. Aquí hay mucho rush, un estilo de vida muy acelerado. Allá la vida es más tranquila.

CUADRO 5

\section{PRACTICAS CULTURALES DE LOS HOGARES DOMINICANOS}

\begin{tabular}{lc}
\hline Práctica (N=59) & Porciento \\
\hline Cocina mayormente comida dominicana & 94.9 \\
Habla mayormente español en su casa & 88.1 \\
Compra mayormente en bodegas y supermercados & 86.7 \\
Pertenece a la religión católica & 78.0 \\
Escucha mayormente música dominicana & 65.5 \\
Escucha mayormente la radio hispana & 62.5 \\
Ve mayormente la televisión hispana & 59.3 \\
Lee mayormente en español & 49.1 \\
Celebra mayormente eventos dominicanos & 42.4 \\
\hline
\end{tabular}

La mayoría de los inmigrantes dominicanos que entrevistamos -26 de 37- aún no se han hecho ciudadanos americanos. ${ }^{20}$ La razón más común para este patrón era un perfodo de estadía demasiado corto en los Estados Unidos. La falta de dominio del inglés era una explicación secundaria. Sin embargo, aún los residentes más antiguos y aquellos familiarizados con el inglés se resistían a abandonar su ciudadanía

y puertoriqueños de los barrios más pobres del centro de la ciudad de Nueva York, especialmente en Harlem, El Barrio, el Bronx y Brooklyn. Ultimamente, los dominicanos han incorporado los ritmos del merengue al rap, tanto en los Estados Unidos como en Puerto Rico.

20. Según un artículo del New York Times (1993b), sólo el 18 por ciento de los dominicanos admitidos a los Estados Unidos en 1977 se habían hecho ciudadanos americanos para 1989. La tasa de naturalización de los dominicanos era casi la mitad de la de todos los inmigrantes durante el mismo período. Para aumentar su representación en la política americana, las asociaciones dominicanas en Nueva York y Nueva Jersey, tales como Alianza Dominicana, constantemente promueven la naturalización de los inmigrantes dominicanos. 
dominicana. "No me interesa", "Me siento dominicano" y "No pienso vivir aquí para siempre" fueron algunas explicaciones adicionales. Por otro lado, muchos dominicanos se hacen ciudadanos americanos por motivos prácticos más que ideológicos. "Quería traer a mi familia acá", dijeron varios entrevistados. "Después de viejo no puede uno estar bregando todos los días en un tirijala cambiando tarjeta y haciendo fila" en el aeropuerto, dijo Rosa. Antonio se hizo ciudadano "buscando no tener que renovar la residencia cada vez que regreso a mi país". "Lo hice por conveniencia", contestó Daniel. Sólo un dominicano dijo que se había hecho ciudadano porque quería "participar en la vida civil" de los Estados Unidos. La mayoría no percibía ninguna ventaja material de ser ciudadano americano, más allá de "pedir" a sus familiares a los Estados Unidos.

Nuestras entrevistas confirmaron la fuerza de la ideología del retorno entre los inmigrantes dominicanos. Dos de cada tres entrevistados dijeron que les gustaría regresar a vivir en su pars ${ }^{21}$. Tres de cada cuatro han vuelto de visita al menos dos veces en los últimos cinco años. El caso más extremo fue el de Daniel, quien estimó que había regresado 50 veces desde que llegó a Nueva York en 1968. Habŕa vuelto cuatro veces en el último año. "Me encanta ir a pasear", dijo.

Cuando se les preguntó por qué querían vivir en su país, los informantes establecieron una clara dicotomía entre "aquí" y "alla". 22 Aqui es donde pueden ganar y ahorrar dinero, progresareconómicamen-

21. En comparación, un estudio reciente encontró que alrededor de la mitad de los colombianos en Queens planeaba regresar a su país (Institute for Puerto Rican Policy 1992).

22. Esta oposición binaria es típica de la mentalidad de otros migrantes circulares como los puertorriqueños. En su cuento "La guagua aérea", el escritor puertoriqueño Luis Rafael sánchez (1987:24) ha retratado a "los puertorriqueños que quieren estar allá pero se tienen que quedar acá: los puertorriqueños que quieren estar allá pero no pueden quedarse allá; los puertorriqueños que viven allá pero sueñan con estar acá: los puertorriqueños cuyas vidas cuelgan de los signos de interrogación ¿allá? ¿acá?, disyuntivas hamletianas que supuran su sangre vital por ambos adverbios". Al igual que los puertorriqueños, los dominicanos constantemente circulan entre los Estados Unidos y la República Dominicana, aunque sea solo temporalmente. 
te, ayudar a sus familias y asegurar un futuro mejor para sus hijos. Pero "aqứ uno vive con puertas cerradas y sin patio", anotó Noelia. Como explicó Pepín.

El sistema de vida es diferente aqui. Aquí la vida tiene más ajetreo. Allá es más pacífica, más suave.

Allá está "mi país": un lugar donde uno pertenece, disfruta, descansa, vive con paz y alegría. "Allá uno goza de mucho placer", dijo Rosa. Estela explicó:

Me fascina mi paŕs. Allá en mi tierra -en San Pedro de Macorís- no hace tanto calor como aquí, especialmente si vives cerca del mar. No estoy allá porque toda mi familia está aquí.

"Allá es que está lo bueno", resumió un informante.

La mayoría de los inmigrantes se siente más a gusto en la República Dominicana que en los Estados Unidos. Aún después de vivir varias décadas en Nueva York, los dominicanos no abandonan totalmente su apego emocional al país natal. Muchos envejecientes planean retirarse en la Isla porque, como señaló Mercedes, "cuando uno está viejo es mejor estar en su país". Otra Mercedes señalo: "Si me enfermo de muerte, que me lleven a morir a mi país". Antonio dijo:

Me siento mejor allá. Camino para todas partes. No me duele nada como aquí. Si Dios permite, me regreso.

Hasta Héctor, un joven dominicano criado en Nueva York que nunca ha regresado a su país, sentía que no pertenecía a la sociedad norteamericana: "éste no es mi país", explicó. "Aquí me siento arrimada", dijo una mujer. Según Dersis, "regresar es el sueño de todo extranjero. Así que estoy preparando el puente para regresar algún día". Rosa recalco: "uno siempre sueña con volver a su madre tierra". Un bodeguero se lamento:

Tengo siete meses que no he ido [a la República Dominicana] y la nostalgia de irme me está matando. Ya estoy casi allá. 
En síntesis, los dominicanos comparten una imagen romántica de su patria, en contraste con su situación actual en los Estados Unidos. " $\mathrm{Y}$ qué será lo que la gente le encuentra a esto aquin?" se preguntó Ana Sofía retóricamente. Otro informante le contest 6 : "No hay mejor lugar para vivir que mi país". Este desdoblamiento entre un espacio inmediato y otro remoto, entre el presente y el pasado, entre la realidad y la nostalgia, es un rasgo común de la identidad transnacional.

\section{Discusión}

Los hallazgos de este estudio se discutirán en función de las cinco hipótesis básicas enumeradas al principio del ensayo. En conjunto, los resultados confirman que los dominicanos han creado una comunidad transnacional en Washington Heights que se resiste a la disolución cultural. La identidad de los migrantes combina elementos culturales de la sociedad emisora y la receptora, con un predominio de la emisora. La comunidad dominicana de Washington Heights define, afirma y expresa su identidad híbrida mediante la cultura popular, especialmente a través del lenguaje diario, la comida, la música y la religión.

La orientación cultural hacia la República Dominicana. Al igual que otros estudios previos, nuestros datos sugieren que los dominicanos en Nueva York frecuentemente recurren a las creencias y costumbres tradicionales de su país natal. Este apego continuo a la cultura de origen tiene varias explicaciones. Por un lado, el éxodo dominicano no sólo es relativamente reciente, sino que aumentó en la década de 1980 como resultado del deterioro en las condiciones de vida en la República Dominicana y la disponibilidad de empleos poco diestros en los Estados Unidos y Puerto Rico. El éxodo probablemente continuará en la década de 1990, renovando la comunidad dominicana en el exterior.

Por otro lado, la concentración geográfica de los inmigrantes en Washington Heights ha creado un núcleo poblacional suficientemente grande para reproducir muchas instituciones dominicanas. Más aún, las facilidades de transportación y comunicación entre la República Dominicana y los Estados Unidos permiten un flujo constante de ideas. 
Docenas de asociaciones voluntarias han mantenido vivo el recuerdo de la patria lejana en Washington Heights. La segregación residencial y el prejuicio racial han promovido la encapsulación de los inmigrantes y un contacto limitado con otros hispanos en Nueva York. Finalmente, una incipiente economía de enclave ha fortalecido los lazos de solidaridad étnica en vez de la cooperación interétnica.

La creación de una identidad transnacional. La migración internacional y el asentamiento en un ambiente hostil han transformado la cultura popular de los dominicanos en Washington Heights. La mayoría de los inmigrantes no mantiene su cultura intacta sino que se acultura con el paso del tiempo y un mayor intercambio con la comunidad receptora. Esta tendencia es especialmente evidente entre los jovenes dominicanos. Por ejemplo, muchos adolescentes dominicanos usan el "espanglish", intercalando códigos lingüísticos del español y el inglés, como su modo primario de comunicación.

Sin embargo, pocos inmigrantes han abandonado por completo su identidad dominicana, aún después de vivir mucho tiempo en los Estados Unidos. A la nueva generación de dominican-yorks, nacida y criada en los Estados Unidos, le disgusta el término "domínicoamericano". 23 La mayoría de los inmigrantes dominicanos aún no se han hecho ciudadanos americanos ni han adquirido el inglés como su lengua materna. La mayoría tiene intenciones de regresar eventualnente a la República Dominicana y visita regularmente la Isla. Los periódicos étnicos cubren eventos importantes tanto de la República Dominicana como de la comunidad dominicana de Nueva York y Nueva Jersey. Las actitudes ambivalentes hacia la sociedad anfitriona caracterizan a la comunidad inmigrante, dividida entre el deseo de progresar económicamente en los Estados Unidos y el persistente apego emocional a la República Dominicana. Un sentido de dualidad permea a la comunidad dominicana de Washington Heights, desde sus preferencias televisivas hasta sus patrones de participación política. En suma, la dicotomía entre el aquí y el allá estructura la mentalidad de los dominicanos en Nueva York.

23. Entrevista con Idanys Rodríguez, Coordinador de la Unión de Jóvenes Dominicanos, Nueva York, 23 de julio de 1993. 
La cultura popular y la identidad étnica. A la mayoría de los inmigrantes dominicanos se les hace difícil articular las bases de su identidad colectiva. Pero expresan esa identidad claramente a través de la cultura popular. El índice más fuerte de su origen nacional es la comida criolla, seguida de la preferencia por hablar español, comprar en tiendas del vecindario y practicar la religión católica. Los inmigrantes también favorecen la música dominicana así como la radio y la televisión en español, aunque en menor grado. Más aún, los residentes dominicanos de Washington Heights despliegan su identidad rindiéndole culto a los santos, poniendo banderas y mapas nacionales en las paredes y escuchando merengues y bachatas a todas horas del día. Aunque muchos inmigrantes no pueden explicar exactamente qué distingue a la cultura dominicana de otras culturas, los signos de su identidad son visibles y audibles.

Una cultura en los márgenes. La mayoría de los dominicanos se ha incorporado a los niveles más bajos del mercado de trabajo y vivienda de Nueva York. El prejuicio étnico y la discriminación racial los han excluído sistemáticamente de la corriente principal de la sociedad norteamericana. Los estereotipos negativos promovidos por los medios de comunicación han estigmatizado a toda la comunidad dominicana como narcotraficantes y mafiosos. Las tensiones ocasionales y la competencia constante con los puertorriqueños y otros hispanos han dificultado las alianzas políticas. Como consecuencia, los dominicanos ocupan una posición marginal dentro de la estructura de los grupos étnicos en Nueva York. Bajo tales circunstancias, "la asimilación' puede no ser a los valores y las expectativas de la cultura dominante, sino a la postura adversarial de los grupos empobrecidos, confinados a la parte inferior del reloj de arena económico" (Portes y Zhou 1993:12-13; mi traducción).

La resistencia a la asimilación. Al igual que otros inmigrantes caribeños en los Estados Unidos, la comunidad dominicana de Washington Heights no se ha asimilado lingüistica y culturalmente, sino que conserva gran parte de su legado cultural. La concentración de grandes contingentes de extranjeros pobres y de piel oscura en barrios del centro 
de la ciudad los ha deprivado de la oportunidad de interactuar con otros grupos étnicos, aprender inglés y adquirir las destrezas necesarias para incorporarse a la cultura dominante en los Estados Unidos. Muchos dominicanos mantienen una distancia emocional de la sociedad norteamericana y se sienten ajenos a su cultura. Los viajes de ida y vuelta a la República Dominicana refuerzan la mentalidad transeúnte y la ideología de retorno de los residentes en el exterior. La mayoría de los dominicanos ve la emigración como una etapa temporal en su ciclo vital, no como una decisión irreversible que lleva a la completa absorción en el crisol norteamericano. La patria sigue siendo el punto de referencia clave para entender la visión de mundo de los migrantes.

\section{Conclusión}

Aunque los contomos socioeconomicos de la migración dominicana se han dibujado claramente, la vida cotidiana de los dominicanos en Nueva York se mantiene fuera de los límites del discurso académico o, para citar la apta frase de Silvio Torres-Saillant (1991), en "la periferia del margen". Al concentrarse en los componentes estructurales del proceso migratorio, la mayoría de los académicos ha subestimado las dimensiones culturales del éxodo dominicano. Con pocas excepciones (Torres-Saillant 1989a; Rey Hemández 1992), los investigadores no han penetrado más allá de las estadísticas socioeconómicas para interpretar los valores, las costumbres y la visión de mundo de los migrantes dominicarios. Y sin embargo este proceso de transportar, recrear y transformar un estilo de vida siempre ha sido central en la experiencia migratoria en Nueva York. Como resultado de los intereses prevalecientes de los investigadores académicos, los dominicanos han sido retratados como obreros sin cultura propia, mezclándose imperceptiblemente dentro del crisol de razas norteamericano (véase Torres-Saillant 1989a para una crítica de esta tendencia).

Estudios recientes han subrayado la erosión de las distinciones étnicas entre los descendientes de inmigrantes europeos en los Estados Unidos (Alba 1990). La identidad étnica basada en un origen europeo particular ha perdido importancia como modo de organizar las interaccion social. En cambio, ha surgido un nuevo grupo basado en el origen en 
cualquier país europeo como sector dominante de la sociedad norteamericana. Sinembargo, la formacion de la identidad difiere sustancialmente entre los norteamericanos blancos y otros grupos étnicos y raciales, especialmente los afro-americanos y los hispanos (Portes y Zhou 1993). Por ejemplo, la mayoría de los inmigrantes caribeños en los Estados Unidos no quisiera abandonar su país natal definitivamente y su estadía en la sociedad anfitriona frecuentemente retiene un carácter provisional (Chaney 1987). A diferencia de la mayoría de los inmigrantes europeos, los inmigrantes caribeños se mantienen en contacto constante con sus culturas. La circulación permanente de personas entre el Caribe y la ciudad de Nueva York ha generado múltiples comunidades e identidades transnacionales.

El presente estudio documenta el surgimiento de una identidad transnacional en la comunidad dominicana de Washington Heights. Esta identidad se caracteriza por un apego ambivalente a la sociedad anfitriona y una orientación persistente hacia el país de origen. Aunque las redes de parentesco y amistad cubren a ambos países, las creencias y las costumbres culturales se basan firmemente en la sociedad emisora. El lugar de origen, no el de destino, provee el principal marco de referencia para la mayoría de los inmigrantes.

Washington Heights sirve como un punto intermedio de asentamiento, un lugar donde los dominicanos pueden hablar español, conocer a otros compatriotas, asistir a misa en español, comprar en bodegas, comer comida criolla, escuchar merengue y mantenerse encapsulados en una cultura hispana. Las asociaciones voluntarias y la celebración de eventos públicos no representan la expresión primaria de la identidad étnica en el barrio, sino las prácticas informales de la vida cotidiana. A través de la cultura popular, especialmente el lenguaje oral, la música, la comida y la religión, los dominicanos celebran su sentido de pertenecer a un grupo definido por su origen nacional, composicion racial y pasado compartido. En esencia, Washington Heights nutre el espíritu de una comunidad moral entre los inmigrantes dominicanos en Nueva York, reinventando así a Quisqueya en el Hudson. 


\section{Bibliografía}

Abeles, Peter, y Robert C. Weinberg

1968 Washington Heights Community Study. Nueva York: Department of City Planning, City of New York.

Alba, Richard D.

1990 Ethnic Identity: The Transformation of White America. New

Haven: Yale University Press.

Alvelo, Jaime et al.

1981 Impact of New Immigrants on the Delivery of Social Services

in Washington Heights. Working Paper, Doctoral Research Seminar,

School of Social Work, Columbia University.

Bolton, Reginald Pelham

1924 Washington Heights, Manhattan: Its Even I Past. Nueva York:

Dyckman Institute.

Brownrigg, Leslie A.

19901990 Guidelines for the Altemative Enumeration. Part One:

Geography and Physical Space. Center for Survey Methods Research,

Bureau of the Census, Washington, D.C. Fotocopia.

Brownrigg, Leslie A., y Elaine Fansler

1990 1990Guidelines for the Alternative Enumeration. Part Three:

Behavioral Observations. Center for Survey Methods Research, Bureau of the Census, Washington, D. C. Fotocopia.

Chaney, Elsa $M$.

1987 The Context of Caribbean Migration. En Constance R. Sutton y Elsa M. Chaney, eds., Caribbean Life in New York City: Sociocultural Dimensions, pp. 3-14. Nueva York: Center for Migration Studies of New York.

Chavez, Leo

1993 The Power of the Imagined Community: The Settlement of Undocumented Mexicans and Central Americans in the United States. Manuscrito inédito.

Columbia-Presbyterian Medical Center

1983 Washington Heights-Inwood Community Pro ,file. Nueva York: Columbia-Presbyterian Medical Center. 
Dominguez, Virginia

1978 Show Your Colors: Ethnic Divisiveness Among Hispanic Caribbean Migrants.

Migration Today 6 (I):5-9.

1973 Spanish Speaking Caribbeans in New York: "The Middle Race." Revista/Review Interamericana 3 (2):135-142.

Duany, Jorge

1992 Caribbean Migration to Puerto Rico: A Comparison of Cubans and Dominicans.

International Migration Review 26 (l):46-66.

1991 El sector informal y la migración internacional: El caso de los dominicanos en Puerto Rico. Nueva Sociedad 113:16-27.

Duany, Jorge, ed.

1990Losdominicanos en Puerto Rico: Migración en la semi-periferia. Río Piedras: Huracán.

Duany, Jorge, Luisa Hernández Angueira y César A. Rey

1993 El Barrio Gandul: Economía subterránea y migración indocumentado. Manuscrito inédito.

Duany, Luis A.

1987 Fostering Puerto Rican Small Businesses as a Device for Economic Development. Manuscrito inédito. New York Area Undergraduate Research Program, Columbia University.

El Diario/La Prensa

1993a Asesinan a dos "súpers" en el Alto Manhattan. 28 de junio. p. 4.

1993b Balean a dos en Washington Heights. 22 de julio, p. 4.

1993c Después de muchos años de división: Acuerdo en desfile dominicano. 21 de julio, p. 8 .

1993d Detectan fraude masivo en el sistema de bienestar público. 24 de junio, p. 3.

1993e Escolares presionan al MTA. 17 de junio, p. 3.

1993f Este domingo: Gran Parada Dominicana de El Bronx. 14 de julio, p. 8.

1993g Mal negocio con la Policía: Arrestan a tres comerciantes dominicanos por soborno. 17 de junio, p. 4.

1993h Otra muerte calienta los ánimos en el alto Manhattan. 12 de julio, p. 3.

1993i Una pasión equivocada. 22 de julio, p. 3. 
1993j Washington Heights, desde el “rufo". 30 de julio, p. 19. Elinson, Jack, y Regina Loewenstein

1963 Community Fact Bookfor Washington Heights, New York

Cit,,V: 1960-61. School of Public Health and Administrative Medicine,

Columbia University.

Fiske, John

1989 Understanding Popular Culture. Boston: Unwin Hyman.

Flores, Juan

1988 Rappin', Writin', \& Breakin'. Boletín del Centro de Estudios

Puertorriqueños 2 (3):34-41.

García Canclini, Néstor

1982 Las culturas populares en el capitalismo. Ciudad México:

Nueva Imagen.

Garrison, Vivian, y Carol l. Weiss

1979 Dominican Family Networks and United States Immigration

Policy: A Case Study.

Intemational Migration Review 12 (2):264-283.

Georges, Eugenia

1990 The Making of a Transnational Community: Migration, Development, and Cultural Change in the Dominican Republic. Nueva York: Columbia University Press.

1988 Dominican Self-Help Associations in Washington Heights: Integration of a New Population in a Multiethnic Neighborhood. New Directions for Latino Public Policy Research, Working Paper No. 1, Inter-University Program for Latino Research and the Social Science Research Council.

1984 New Immigrants and the Political Process: Dominicans in New York. Occasional Paper No. 45. Center for Latin American and Caribbean Studies, New York University.

Grasmuck, Sherri

1985 The Consequences of Dominican Urban Outmigration for National Development: The Case of Santiago. En Steven Sanderson, ed., The Americas in the New International Division of labor, pp. 145-176. Nueva York: Holmes \& Meier.

1984 Immigration, Ethnic Stratification, and Native Working-Class Discipline: Comparisons of Documented and Undocumented Dominicans. Intemational Migration Review 18 (3):692-713. 
1991 Between Two Islands: Dominican Intemational Migration.

Berkeley: University of Califonia Press

Hendricks, Glenn

1974 The Dominican Diaspora: From the Dominican Republic to New York City-Villagers in Transition. Nueva York: Teachers College Press.

Henriques, Beth

1984 A Historical Planning Study of Washington Heights, 1900-1935.

Tesis de maestría, Graduate School of Architecture and Planning, Columbia University.

Hernández, Ramona

1989a Mercado de trabajo de los dominicanos en Nueva York. En Juan Hernández Cruz, ed., Los inmigrantes indocumentados dominicanos en Puerto Rico: Realidad y mitos, pp. 77-96. San Germán: Centro de Publicaciones, Universidad Interamericana de Puerto Rico.

$1989 \mathrm{~b}$ Notes on the Incorporation of Dominican Workers into the Labor Market of New York City. Punto 7 Review: A Journal of Marginal Discourse 2 (I):65-90. 1989c Trends in Dominican Labor Migration Research. Ponencia presentada en el XV Congreso Intermacional de la Asociación de Estudios Latinoamericanos, Miami, Florida, diciembre.

Hispanic Market News

1993 En ceremonia especial se instala nueva directiva de la Asociación Nacional de Supermercados. Volumen 7, Números 6/7 (junio-julio), p. 2.

Institute for Puerto Rican Policy

1992 Latino Intergroup Relations in the New York Area: October 1991. Datanote on the Puerto Rican Community Number 8 (enero).

Katznelson, Ira

1981 City Trenches: Urban Politics and the Patterning of Class in the United States. Nueva York: Pantheon.

Larancuet, Wilfredo N., Luis Alvarez-López, y Miriam Mejía

1991 Actitud de los votantes en Washington Heights. Manuscrito inédito, Center for Dominican Studies, New York.

Lendt, Lee

1960 A Social History of Washington Heights, New York City. 
Columbia-Washington Heights Community Mental Health Project,

Columbia University, Faculty of Medicine.

Lewis, Gordon K.

1982 Migration and Caribbean Consciousness. En Migration and

Carilbbean Cultural Identity. Occasional Paper No. 1, Caribbean

Migration Program, Center for Latin American Studies, University of

Florida, Gainesville.

Lowenstein, Steven $M$.

1989 Frankfurt on the Hudson: The German-Jewish Community of

Washington Heights,

1933-1983, Its Structure and Culture. Detroit: Wayne State University.

Mahler, Sarah

1989 La dinámica de la legalización en Nueva York: Un enfoque hacia los dominicanos.

En Eugenia Georges et al., Dominicanos ausentes.- Cifras, políticas, condiciones sociales, pp. 139-181. Santo Domingo: Fondo para el Avance de las Ciencias Sociales/Fundación Friedrich Ebert.

McLain, Daisan

1991 Uptown and Downhome: The Indestructible Beat of Santo

Domingo. Rock \& Roll Quarterly (Winter):13-15, 19.

Necos, Belkis

1993 Profile of the Dominican Community in New York City.

Informe preliminar presentado en la Conferencia sobre Asuntos de Investigación Dominicana, Institute for Dominican Studies, City College of New York, 5 de junio. New York City, Department of City Planning 1992 The Newest New Yorkers: An Analysis of Immigration into

New York City During the 1980s. Nueva York: Department of City Planning.

1985 Manhattan Community District 12: Washington HeightsIInwood. Nueva York:

Department of City Planning.

New York Daily News

1993 Washington Hgts. Cops Lower Boom. 13 de junio, p. 24.

New York Newsday

1993a Dirty Pool--Girl Assaulted at Washington Hts. Spa; 3 Teens

Held. 12 de julio, p. 3.

1993b Hot on Trial--Cops Name Suspected Firebomber. 12 de julio, p. 5 . 
1993c Judge Riles Dominicans- Ties Them to Fraud. 24 de junio, p. 7.

1993d Tensions Flare Firemen Hurt By Firebomb in Wash. Hts. 11 de julio, p. 3.

1993 e Trying to Make Sense of Census. 24 de junio, p. 8.

Noticias del Mundo 4.

1993a Atacan a policías en Washington Heights. 30 de julio, pp. 1,

1993b Autoridades decomisan armas y drogas en redada Washington Heights. 25 de junio, p. 54.

1993c "Bolita" y sobomo: Se realizaron detenciones en el Alto Manhattan. 17 de junio, pp. $1 \mathrm{~A}, 4 \mathrm{~A}$.

Pessar, Patricia R.

1987 The Dominicans: Women in the Household and the Garment Industry. En Nancy Foner, ed., New Immigrants in New York, pp. 103-129. Nueva York: Columbia University Press.

1985 The Role of Gender in Dominican Settlement in the United States. En June Nash y Helen 1 . Safa, eds., Women and Change in Latin America, pp. 273-294. South Hadley, Mass.: Bergin \& Garvey.

Portes, Alejandro, y Luis E. Guarnizo

1991 Capitalistas del trópico: La inmigración en los Estados Unidos y el desarrollo de la pequeña empresa en la República Dominicana. Santo Domingo: Facultad Latinoamericana de Ciencias Sociales, Proyecto República Dominicana.

Portes, Alejandro, y Min Zhou

1993 The New Second Generation: Segmented Assimilation and its Variants among Post 1965 Immigrant Youth., Russell Sage Foundation, Workíng Paper \#34.

Protestant Council of Churches of the City of New York, Department of Church Planning and Research

1954 Upper Manhattan: A Community Study of Washington Heights. Nueva York:

Protestant Council of Churches of the City of New York.

Rey Hernández, Cesar A.

1992 El reto de la identidad ante la migración: Un reconocerse en el otro. Ponencia presentada en el XVII Congreso Internacional de la 
Asociación de Estudios Latinoamericanos, Los Angeles, Califomia, septiembre.

Rowe, William, $y$ Vivian Schelling

1991 Memory and Modemity: Popular Culture in Latin America.

Londres: Verso.

Sainz, Rudy Anthony

1990 Dominican Ethnic Associations: Classification and Service

Delivery Roles in Washington Heights. Disertación doctoral, Columbia University.

Sánchez, Luis Rafael

1987 The Flying Bus. En Asela Rodríguez de Laguna, eds., Images

and Identities: The Puerto Rican in Two World Contexts, pp. 17-25.

New Brunswick, N.J.: Transaction.

Sassen-Koob, Saskia

1979 Formal and Informal Associations: Dominicans and Colombians

in New York City.

Intemational Migration Review 13 (2):314-332.

Sepúlveda Castillo, Rafael J.

1982 Community Environment: Its Assessment and Relationship to

Psychological WellBeing Among Dominicans and Puerto Ricans in New York Ciry. Disertación doctoral, New York University.

Sutton, Constance R., y Elsa M. Chaney, eds.

1987 Carlbbean Life in New York City: Sociocultural Dimensions.

Nueva York: Center for Migration Studies of New York.

The New York Times

1993a Fire Truck is Bombed; 3 Are Hurt--Officials Act to Calm

Washington Heights. 11 de julio, Metro Report, p. 29.

1993b Immigrants Foregoing Citizenship While Pursuing American

Dream. 25 de julio, pp. 1, 33.

199la Between 2 Worlds: Dominicans in New York. 16 de septiembre, pp. Al, B6.

199lb Dominican Club Offers Home in a Foreign Land. 8 de mayo.

199lc Dominican Joumal: Filthy Rich with a New York Cocaine

Connection. 8 de junio.

199ld Farmer Unearthed: He Planted the Com. 15 de agosto.

1990 Tap Dancers and Parade Welcome Sun's Return. 13 de agosto.

Torres-Saillant, Silvio

1991 La literatura dominicana en los Estados Unidos y la periferia 
del margen. Punto y coma 3 (1-2):139-149.

1989a Dominicans as a New York Community: A Social Appraisal. Punto 7 Review.- A Journal o Marginal Discourse 2 (1):7-25.

1989b The Construction of the Other in Studies of Dominican Migration. Ponencia presentada en el XV Congreso Internacional de la Asociación de Estudios Latinoamericanos, Miami, Florida, diciembre. Village Voice

1992a After "Kiko: "The Dominican Community Emerges. 21 de julio, pp. 13-14.

1992b Marginal Notes. 18 de agosto, p. 21.

1992c News Before lt Happens. 9 de septiembre, p. 17.

1988 Desfile Dominicano: Getting Off on a Good Foot. 8 de agosto. pp. 11-12. Washington Heights Taxpayers Association 1920 Riverside Drive and Audubon Park. Nueva York: Washington Heights Taxpayers Association. 